Víctor Jeifets y Lazar Jeifets, La inserción internacional de la izquierda comunista anti-gomecista en el exilio venezolano, primeros años - The international insertion of the Communist Left-Wing anti-Gómez tendency of the Venezuelan exiles, the first years, Revista Izquierdas, 25, octubre 2015, IDEA-USACH, ISSN 0718-5049, pp. $1-28$

\title{
La inserción internacional de la izquierda comunista anti-gomecista en el exilio venezolano, primeros años
}

\author{
The international insertion of the Communist Left-Wing anti-Gómez tendency \\ of the Venezuelan exiles, the first years
}

\author{
Víctor L. Jeifets ${ }^{*}$ y Lazar S. Jeifets ${ }^{* *}$
}

\begin{abstract}
Resumen: El artículo analiza la etapa previa a la formación 'oficial' del Partido Comunista de Venezuela, a partir de los «precursores » del comunismo nacional y sus relaciones con los grupos de exiliados políticos y la Internacional Comunista. Sobre la base de los documentos de la Comintern resguardados en Moscú, y algunos otros archivos, los autores recuperan una historia poco conocida en la historiografía de la izquierda venezolana.
\end{abstract}

Palabras clave: Partido Comunista de Venezuela; Partido Revolucionario Venezolano; Internacional Comunista, Exilio, Gustavo Machado, Salvador de la Plaza, Antiimperialismo, 'Camino Garibaldino'

\begin{abstract}
The article analyzes the stage before to the 'official' formation of the Communist Party of Venezuela from the point of studying of the relations between the "precursors" of the national communism with the groups of political exiles and with the Communist International. On the base of the Comintern documents kept in Moscow, as well as files of some other archives, the authors are recovering the slightly studied history which is poorly reflected in the historiography of the Venezuelan LeftWingers.
\end{abstract}

Keywords: Communist Party of Venezuela, Venezuelan Revolutionary Party, Communist International, exiles, Gustavo Machado, Salvador de la Plaza, antiimperialism, 'Garibaldian way'

\footnotetext{
"Ruso. Doctor titular, profesor de la catedra de Teoria e Historia de las Relaciones Internacionales de St. Petersburg State University (SPbSU) y profesor de la State University of Aerospace Instrumentation (SUAI). Autor y coautor de varios libros y artículos sobre relaciones internacionales e historia de la izquierda latinoamericana. jeifets@gmail.com El artículo fue preparado dentro del marco del proyecto de investigación núm. 15-31-01016 apoyado por el Fondo Científico Ruso de Humanidades.

${ }^{* *}$ Ruso. Doctor titular, profesor de la catedra de Estudios Americanos de la Universidad Estatal de San Petersburgo; representante del Instituto de América Latina de la ACR en San Petersburgo. Autor y coautor de varios libros y artículos sobre relaciones internacionales e historia de la izquierda latinoamericana. jeifets@gmail.com
} 
Víctor Jeifets y Lazar Jeifets, La inserción internacional de la izquierda comunista anti-gomecista en el exilio venezolano, primeros años - The international insertion of the Communist Left-Wing anti-Gómez tendency of the Venezuelan exiles, the first years, Revista Izquierdas, 25, octubre 2015, IDEA-USACH, ISSN 0718-5049, pp. $1-28$

\section{Introducción}

En la historia de los partidos de izquierda latinoamericana es fácil encontrar para el investigador momentos destacados y dramáticos relacionados con la lucha gloriosa contra las dictaduras y por el cumplimiento de una serie de exigencias y retos sociales. El caso que nos ocupa no es la excepción: el Partido Comunista de Venezuela (PCV), el organismo político más antiguo del país (cumplió 80 años en 2011). En general, la historiografía sobre su desarrollo no es escasa, existen varias obras importantes escritas tanto por los opositores al comunismo como por investigadores fieles al marxismo y la izquierda radical. Todavía durante la existencia de la dictadura de E. López Contreras salió impresa una recopilación de documentos publicados con el objeto de comprobar el carácter "delictivo y conspirativo" de las actividades de este partido. ${ }^{1}$ Luego fueron publicadas memorias de dos destacados dirigentes del PCV, Juan Bautista Fuenmayor y Jesús Fária. También aparecieron varios libros sobre la vida de los 'líderes históricos' del partido, los hermanos Gustavo y Eduardo Machado Morales y Salvador de la Plaza, así como valiosos estudios realizados por el prominente historiador Manuel Caballero. ${ }^{2}$

No obstante, la historia del PCV todavía está llena de lagunas significativas y momentos desconocidos. La fecha oficial de fundación, el 5 de marzo de 1931, no refleja la complicada historia de las relaciones entre los comunistas venezolanos y la III Internacional Comunista (la Comintern). Por lo tanto, uno de los desafíos para la historiografía del PCV consiste en la establecer criterios para una cronología de los primeros años de existencia del partido. Hace mucho tiempo, el Comité Central del PCV creó una comisión especial dirigida por E. Gallegos Mancera (miembro del Buró Político del CC) cuya tarea era definir en qué momento los comunistas habían empezado a actuar como una fuerza organizada dentro del espectro político de Venezuela. La comisión determinó que el 5 de marzo de 1931 (inicio de actividades de la primera célula del PCV) debía considerarse como la fecha oficial de la fundación del Partido Comunista. Sin embargo, este punto de vista no fue compartido por R. J. Cortés, miembro del Buró Político y Secretario del CC del PCV. Cortés insistía que el camino histórico del partido había que contarlo a partir del momento

\footnotetext{
${ }^{1}$ Libro Rojo del General López Contreras. 1936. Documentos robados por espías de la policía política (Caracas: Ávilarte, 1975).

2 Juan Bautista Fuenmayor. Aportes para la historia del P.C.V. (Maracaibo: Biblioteca de Documentos Históricos, 1971); Juan Bautista Fuenmayor. 1928-1948. Veinte años de política (Caracas: s.e., 1968); Gustavo Machado. De oligarca a comunista. 1914/1974 (Caracas: Ediciones Centauro, 1975); Irene Rodríguez Gallad. Compilación, Introducción, Cronología y Notas. Archivo de Salvador de la Plaza. Tomos I-II (Caracás: Ediciones Centauro, 1992); Manuel Caballero. Entre Gómez y Stalin (Caracas: Universidad Central de Venezuela, Consejo de Desarrollo Científico y Humanístico, 1989); Manuel Caballero. La Internacional Comunista y la revolución latinoamericana (Caracas: Editorial Nueva Sociedad, 1987); Manuel Caballero. La Internacional Comunista y América Latina: La sección venezolana (México: Pasado y Presente, 1978); Jesús Faria. Stanovleniie kommunista. Vospominaniia (Moscú: Izdatelstvo politicheskoi literatury, 1983); Guillermo García Ponce. Memorias de un general de la utopía.La increíble historia de un venezolano excepcional, Eduardo Machado y de sus luchas revolucionarias en Venezuela, Cuba, México, España, Estados Unidos y en la Internacional Comunista (Caracas: Cotragraf, 1992).
} 
Víctor Jeifets y Lazar Jeifets, La inserción internacional de la izquierda comunista anti-gomecista en el exilio venezolano, primeros años - The international insertion of the Communist Left-Wing anti-Gómez tendency of the Venezuelan exiles, the first years, Revista Izquierdas, 25, octubre 2015, IDEA-USACH, ISSN 0718-5049, pp. $1-28$

de inauguración de su Primera Conferencia Nacional (8 de agosto del año 1937). La comisión se basaba, entre otras cosas, en el reconocimiento del PCV como sección nacional de la Comintern por el VII Congreso Mundial de la Internacional (1935). ${ }^{3}$

Este criterio, obviamente, se refería a la inserción internacional del PCV, un momento clave para cualquier Partido Comunista de aquella época. Consecuentemente, la historia 'oficial' de PCV se concentra en las decisiones de la III Internacional de fomentar el desarrollo de los Partidos Comunistas en todo el mundo, con el objeto de organizar a las masas proletarias y luchar por el poder y contra el imperialismo. Los hermanos Fortoul fueron enviados a Venezuela por el Buró del Caribe del Comité Ejecutivo de la Comintern precisamente con el propósito de coordinar los esfuerzos de los grupos comunistas dispersos que ya habían surgido y empezaban a actuar dentro de Venezuela. ${ }^{4}$ Así, la historia de los contactos de los comunistas venezolanos con la Comintern se cuenta a partir del año 1931.

Sin embargo, este mismo criterio -la inserción internacional- no deja estar de acuerdo con la fecha propuesta como el momento de la formación del comunismo venezolano. Los documentos de los archivos permiten observar que los contactos de los comunistas de Venezuela con Moscú, así como con varios Partidos Comunistas latinoamericanos y de EE.UU., fueron establecidos años antes de la fecha 'oficial' del surgimiento del PCV. Es cierto que algunos episodios de la actividad de los primeros comunistas venezolanos están mencionados en la literatura, pero los autores no buscaban establecer los vínculos entre éstos y la fundación posterior de la sección venezolana de la Comintern. ${ }^{5}$ Así, en el prólogo al folleto de F.Key Sánchez, Gallegos Mancera afirmaba que

bajo el impacto de los grandes desarrollos revolucionarios que estaban ocurriendo en esa época, una apreciable cantidad de exilados antigomecistas rompían con los esquemas tradicionales de las luchas políticas en Venezuela (conspiraciones, asonadas, "golpes" encabezados por "generales" y caudillos) y eran ganados para la ideología marxista-leninista, para la organización y lucha de masas y se afiliaban a los Partidos Comunistas, secciones de la Internacional Comunista, de diversos países. Entre ellos estuvieron: a) Figuras pioneras del PCV como Gustavo Machado y Salvador de la Plaza, que junto con otros revolucionarios latinoamericanos crearon la Liga Antimperialista de América y editaron su órgano " $E l$ Libertador" (1925-1928). Colaboraron en la construcción de los PC de México y Cuba y crearon una importante organización policlasista llamada Partido Revolucionario Venezolano (P.R.V.) que con su órgano, el combativo periódico "Libertad", editado en México (1928-

\footnotetext{
${ }^{3}$ Los miembros de esta Comisión eran los veteranos militantes del movimiento revolucionario, F. Key Sánchez, O. Luzardo, J. Correa, R. J. Cortés, R. Quintero y J. Sanoja Hernández. -Fernando Key Sánchez. Fundación del Partido Comunista de Venezuela. Prólogo de E.Gallegos Mancer. $2^{\mathrm{a}}$ ed. ampliada (Caracas: Fondo Editorial "Carlos Aponte", 1984) 7.

${ }^{4}$ P. Araujo, "80 años de la fundación del Partido Comunista de Venezuela", Tribuna Popular [Caracas]. 13o. en. de 2011.

${ }^{5}$ Tampoco es de mucha ayuda a ese respecto la obra importante del 'patriarca' de los estudios cominternistas latinoamericanos. Véase: Robert J. Alexander. Communist Party of Venezuela (Stanford: Hoover Institution Press, 1969).
} 
Víctor Jeifets y Lazar Jeifets, La inserción internacional de la izquierda comunista anti-gomecista en el exilio venezolano, primeros años - The international insertion of the Communist Left-Wing anti-Gómez tendency of the Venezuelan exiles, the first years, Revista Izquierdas, 25, octubre 2015, IDEA-USACH, ISSN 0718-5049, pp. $1-28$

1930), jugó un gran papel en la elevación del nivel político de la emigración antigomecista venezolana y se proyectó hacia el interior. ${ }^{6}$

Nombró también a Aurelio y Mariano Fortul, Miguel Otero Silva, Eduardo Machado, Ricardo Martínez y otros como participantes del movimiento comunista en Francia y EE.UU.

Apenas una mitad de página para caracterizar el período clave para el movimiento revolucionario, aunque los historiadores 'oficiales' del PCV jamás vuelven a analizar los años iniciales de la formación de la izquierda nacional. En el 80 aniversario del Partido Comunista, el periódico “Tribuna Popular" (cuyo fundador, Gustavo Machado Morales, fue uno de los precursores del PCV) se limita a republicar el texto de Gallegos Mancera sin entrar en los pormenores de los hechos acontecidos en la década de 1920.

Coincidiendo con el planteamiento sobre la necesidad de definir el período inicial del PCV, partiendo del momento de su inserción en el órbita del comunismo internacional, creemos necesario matizar y profundizar el estudio, corrigiendo el error existente en la historiografía. Consecuentemente, dentro de los marcos de presente artículo se pretende recuperar los datos históricos sobre las actividades comunistas dentro del Partido Revolucionario Venezolano (PRV) realizadas por el Grupo Revolucionario Continental.

A través de este texto analizaremos la relación establecida entre los primeros comunistas venezolanos y el Estado Mayor de la revolución mundial con sede en Moscú. Al respecto, sostendremos que estos primeros contactos dejaron en evidencia el surgimiento del "camino garibaldino", como una opción de desarrollo de la izquierda venezolana. Dicha opción se habría caracterizado por la capacidad de los primeros comunistas para salirse de los dogmas ortodoxos del marxismo, estableciendo enlaces con otros grupos antidictatoriales y rebasando a los grupos considerados como apoyos naturales del comunismo. Vemos una necesidad de analizar la postura de la Comintern acerca de los primeros planes de la formación del Partido Comunista venezolano y acerca de los cuadros dirigentes de aquel partido. Los pormenores de esta historia hasta hace poco estuvieron guardados bajo siete llaves y solamente con la apertura parcial del Archivo en la Comintern en Moscú (RGASPI, por sus siglas en ruso) empiezan a aparecer ante el público. Sin embargo, los estudios de la historia del Partido Comunista de Venezuela basados sobre los materiales de RGASPI son escasos, ${ }^{7}$ el partido gobernante en Venezuela, el PSUV, tampoco parece estar muy interesado en averiguar los antecedentes del "socialismo bolivariano del siglo XXI" y del comunismo venezolano.

Para alcanzar nuestros objetivos, hemos elaborado un texto dividido en cuatro secciones. En la primera nos concentraremos en la historia de las primeras actividades de la izquierda venezolana (la Unión Obrera Venezolana y el PRV) surgida en el exterior del país y destacaremos sus primeros puntos de coincidencia con la Comintern y con los aliados

\footnotetext{
${ }^{6}$ Véase, para ejemplo, la obra mencionada de Key Sánchez escrita como resumen del trabajo de la comisión del CC (su primera edición se llamaba "Primera célula comunista en Venezuela, marzo-5-1931), Fernando Key Sánchez. Fundación del Partido Comunista de Venezuela: (trabajo elaborado para el Comité Central y el VI Congreso del P.C.V.) (Caracas: Fondo Editorial “Carlos Aponte”, 1980).

7 Una excepción notable son los estudios realizados por la investigadora alemana-venezolana Dorothea Melcher, sin embargo, no cubren toda la laguna historiográfica existente.
} 
Víctor Jeifets y Lazar Jeifets, La inserción internacional de la izquierda comunista anti-gomecista en el exilio venezolano, primeros años - The international insertion of the Communist Left-Wing anti-Gómez tendency of the Venezuelan exiles, the first years, Revista Izquierdas, 25, octubre 2015, IDEA-USACH, ISSN 0718-5049, pp. $1-28$

nacionalistas revolucionarios latinoamericanos. En segundo lugar, abordaremos el análisis de las relaciones entre la izquierda comunista del PRV y la sede central de la Tercera Internacional. Consideraremos en este contexto la postura tomada hacia el exilio revolucionario en México por los emisarios del Partido Comunista mundial en este país. Además, abordaremos los detalles del viaje de Gustavo Machado y Ricardo A. Martínez a Moscú y sus pláticas sostenidas en la URSS con los funcionarios soviéticos y de la Comintern. En tercer lugar, nos enfocaremos al análisis de las divergencias entre el plan propuesto por la izquierda venezolana ("el camino garibaldino") para derrocar al dictador J.V.Gómez y el concepto del 'partido proletario' sustentado por la Comintern en obvia oposición al primer plan. Caracterizando estas divergencias trataremos de entender cómo influyeron en los cambios personales posteriores de la dirección de la izquierda comunista venezolana y en las rupturas en el seno de ésta. Por último, en la cuarta sección abordaremos la historia del intento fallido de los comunistas venezolanos y sus aliados por organizar una expedición armada en contra de la dictadura venezolana y sus consecuencias para el PRV en su conjunto como para su sección comunista.

Utilizaremos algunas fuentes hemerográficas, sobre todo las que publicaban materiales de la izquierda venezolana en el exilio, para obtener información de los acontecimientos referentes al tema del estudio. Sin embargo, la base principal del artículo serán los documentos de archivos rusos, venezolanos y mexicanos de primera mano, la correspondencia del PRV y del GCR, así como las resoluciones y decisiones oficiales de la Comintern y del Partido Comunista de México.

Obviamente, las resoluciones tomadas y los documentos oficiales no pueden ser la plataforma básica para las investigaciones del tema. Las actuaciones detrás de bambalinas significaban en la Comintern una parte clave del funcionamiento de sus secciones nacionales, lo que enfrenta a los historiadores al reto de estudiarlas a partir del análisis de la correspondencia secreta. Con el propósito de averiguar y cotejar los pormenores de la historia de la izquierda venezolana de aquel período, contrastaremos las fuentes de archivo con la información publicada en la bibliografía existente y las memorias. Tal enfoque permite entender mejor la esencia de la evolución de la izquierda en este país y evaluar de manera precisa los asuntos que no podrían ser discutidos públicamente dado su carácter confidencial.

\section{La formación de centros izquierdistas del exilio venezolano en América Latina y sus primeras actividades}

El gobierno de Juan Vicente Gómez, la autoridad suprema en Venezuela durante varias décadas, era, efectivamente, una dictadura envuelta en las tradiciones formales de constitucionalidad. Gómez llegó a considerarse como el dueño del país y era el mayor propietario de terrenos. El general y sus amigos adquirieron las mejores tierras de cultivo y pastizales, monopolizando luego la venta de carne. Gómez también aprovechó el primer auge petrolero en Venezuela. En 1925 el petróleo había desplazado al café como primer producto de exportación y para 1928 el país alcanzó el primer puesto como exportador de petróleo en el mundo, y el segundo como país productor después de los EE.UU. Esto 
Víctor Jeifets y Lazar Jeifets, La inserción internacional de la izquierda comunista anti-gomecista en el exilio venezolano, primeros años - The international insertion of the Communist Left-Wing anti-Gómez tendency of the Venezuelan exiles, the first years, Revista Izquierdas, 25, octubre 2015, IDEA-USACH, ISSN 0718-5049, pp. $1-28$

permitió al presidente mantener una economía relativamente estable, construir una red de carreteras que unían diferentes ciudades y las plazas militares. Mientras tanto, muchos venezolanos eran analfabetos $(90 \%$ de la población no sabía leer ni escribir). Gómez reprimía con mano dura y sangre fría cualquier intento de oposición antigubernamental. El parlamento nacional era una simple herramienta en las manos del presidente, utilizada con frecuencia para ampliar las facultades del Jefe Supremo. La época gomecista se caracterizó por el nepotismo encubierto, otorgando muchos cargos gubernamentales a miembros de su familia. Gómez se apoyaba en el ejército bien equipado y modernizado. Además, contaba con el apoyo constante de Washington y de las empresas estadounidenses que tenían sus intereses en el sector petrolero de la economía nacional. El gobierno venezolano proponía ofertas y facilidades de inversión a los capitales extranjeros y les permitía exenciones de aduanas, concesiones a largo plazo y beneficios enormes, lo que causaba malestar entre los venezolanos con sentimientos patrióticos y parte de la burguesía nacional. Al mismo tiempo muchos caudillos regionales estaban molestos con la consolidación del poder en las manos del «Gómez Único».

Sin embargo, todas las acciones opositoras fracasaban inevitablemente, la policía y el ejército disolvían las manifestaciones de protesta y prohibían agrupamientos que tomaban posturas independientes del gobierno. La Universidad Central permaneció cerrada desde 1912 a 1925. Las cárceles como La Rotunda en Caracas, el Castillo de Puerto Cabello u otras siempre estaban llenas. En los años de la dictadura las represiones políticas y la miseria hicieron a muchos venezolanos abandonar su patria. Los intentos de crear los partidos y grupos antidictatoriales dentro del territorio nacional siempre fueron reprimidos por el régimen autoritario. Más de 50 mil personas emigraron de Venezuela (sobre todo por razones políticas), una cifra enorme para un país que apenas tenía 3 millones de habitantes.

Los intentos de derrocar a Gómez (organizados por militares descontentos y/o por los jóvenes estudiantes de la llamada generación del 28) nunca salían victoriosos, aunque llenaron la historia de luchas revolucionarios con muchas páginas gloriosas.

Varios grupos opositores de diferente índole política se formaron en el exilio. ${ }^{8}$ Uno de estos era la Unión Obrera Venezolana (UOV) fundada en diciembre de 1923 en Nueva York por J.J. López y L. Muñoz Marín (este último era militante del Partido Socialista Puertorriqueño (PSP) y en el periodo 1949-1964 desempeñó el cargo de gobernador de Puerto Rico) con el fin de reunir a los obreros venezolanos en exilio y capacitarlos para su regreso posterior a la patria.

Desde el inicio la UOV fue una organización más política que sindical. Sus fundadores no tenían intención de ocuparse de asuntos sindicales en los países donde radicaban y, de hecho, difícilmente podrían hacerlo por la dispersión de los miembros de la UOV en varios ramos de la industria. Los dirigentes de la Unión planteaban la necesidad de ingresar en los sindicatos locales para realizar su tarea principal: llevar a cabo la "propaganda revolucionaria entre las masas de emigrados predicando la destitución de la dictadura de

\footnotetext{
${ }^{8}$ Más detalles en: Nikolái P. Kalmykov, et al., ed. Historia de América Latina, 1918-1945 (Moscú: Nauka, 1999) 280; véase también: Manuel Pérez Vila et al. Política y Economía en Venezuela (1810-1976) (Caracas: Ed. Fundación John Boulton, 1976) y Amalio Belmonte Guzmán. Ensayo sobre la historia política de Venezuela, 1917-1968(Caracas: Academia Nacional de la Historia, 1981).
} 
Víctor Jeifets y Lazar Jeifets, La inserción internacional de la izquierda comunista anti-gomecista en el exilio venezolano, primeros años - The international insertion of the Communist Left-Wing anti-Gómez tendency of the Venezuelan exiles, the first years, Revista Izquierdas, 25, octubre 2015, IDEA-USACH, ISSN 0718-5049, pp. $1-28$

Gómez". " La UOV fue admitida al seno de la reformista Federación Panamericana del Trabajo (Pan-American Federation of Labor, PAFL), y los líderes de la Unión guardaban la esperanza de que la influencia y el apoyo de la PAFL pudieran ser útiles para emprender una lucha contra la dictadura gomecista. Sin embargo, el comunismo internacional, la Internacional Sindical Roja (ISR, o Profintern) y la Liga Antimperialista de las Américas (LADLA) tenían una percepción definitivamente negativa de los allegados de Samuel Gompers. ${ }^{10}$ Así, uno de los autores de El Libertador, la revista de la LADLA, planteaba la cuestión: "¿Qué ha hecho la Federación Obrera Pan-americana [así la llamaban a la PAFL en los documentos de la Profintern y la Komintern - V.J, L.J.] por los explotados pueblos de América? ¿Con qué ha contribuido a remediar la espantosa situación de los obreros y campesinos latinoamericanos?", y él mismo respondía amargamente: "Palabras, palabras, y palabras". 11

En la mitad de la década de 1920, los comunistas latinoamericanos empezaron a pensar en transformar a la PAFL en una arma de lucha clasista, involucrando a los delegados de "las grandes organizaciones auténticamente proletarias" de Argentina, Chile y Uruguay en las actividades de la central reformista. Los izquierdistas suponían que la PAFL no iba a tolerar el ingreso de los sindicatos clasistas, pero lo esperaban aprovechar para desplegar una propaganda antiimperialista y antireformista en su próxima convención.

La Comintern y la ISR mandaron a sus partidarios latinoamericanos varias instrucciones acerca de la necesidad de participar en la Convención de la PAFL, pero ya era tarde. De acuerdo con las instrucciones obstruccionistas previas muchos sindicatos ya habían informado al Secretario de la PAFL, Santiago Iglesias, sobre su dimisión de mandar delegados. El representante de la Comintern en México, el suizo Edgar Woog (“Alfred Stirner") logró enviar a los comunistas guatemaltecos y colombianos nuevas instrucciones de Moscú, sin embargo avisó a la Comintern sobre la poca viabilidad de realizarlas, considerando los altos costos de transporte. Propuso como solución enviar las credenciales a los exiliados políticos de Venezuela, El Salvador y Colombia residentes en Nueva York, para que representen a sus sindicatos nacionales. ${ }^{12}$ De esa forma, sólo la UOV (ya liderada por la fracción comunista) obtuvo su chance de exponer abiertamente los puntos de vista de los sindicatos revolucionarios a los líderes y militantes de la central reformista.

Durante la discusión en la V Convención de PAFL (Washington, 1927) el Presidente de la UOV, miembro del Workers' (Communist) Party de América (W(C) PA), el venezolano Ricardo Martínez, junto con el delegado de Nicaragua, propusieron el proyecto de

\footnotetext{
9 "Informe de Salvador de la Plaza", Moscú, 5 de enero de 1928. Archivo Estatal Ruso de la Historia Política y Social, RGASPI, Moscú, F. 534, inv. 7, exp. 95, ff. 32.

${ }^{10}$ Gompers, Samuel (1850 - 1924). Obrero tabaquero. Uno de los fundadores y -a partir del año 1882presidente de la Federación Americana del Trabajo (American Federation of Labor, AFL). El nombre de Gompers se convirtió en un símbolo del reformismo y hasta de las prácticas reaccionarias dentro del movimiento sindical.

${ }^{11}$ R. Cárdenas. "El Congreso Obrero Panamericano", El Libertador, 1.1 (1925): 3-4.

12 "Carta del representante de la Comintern en México, A. Stirner, al jefe del Secretariado Latino J. HumbertDroz”, 27 de mayo de 1927. RGASPI, F. 495, inv.19, exp. 181, ff. 92-100. Citado en: Nikolái P. Kalmykov et al. Komintern y América Latina. Sbornik dokumentov (Moscú: Nauka, 1998) 57.
} 
Víctor Jeifets y Lazar Jeifets, La inserción internacional de la izquierda comunista anti-gomecista en el exilio venezolano, primeros años - The international insertion of the Communist Left-Wing anti-Gómez tendency of the Venezuelan exiles, the first years, Revista Izquierdas, 25, octubre 2015, IDEA-USACH, ISSN 0718-5049, pp. $1-28$

resolución tildando al gobierno estadounidense de imperialista. ${ }^{13}$ Los comunistas nunca tuvieron suficientes fuerzas para derrotar a Gompers en su 'casa' (o sea en las Convenciones de PAFL), sin embargo, los sindicatos revolucionarios lograron expresar abiertamente su actitud beligerante hacia el capitalismo y el reformismo. Pero su alcance fue limitado y, en general, el proyecto de la UOV fue un tiro solitario, y su actividad política se redujo al mínimo tras la salida de Martínez para Moscú.

El centro más activo del exilio político venezolano se formó en México. El régimen gobernante de aquel país -al declarar su fidelidad a los ideales de la Revolución Mexicana de 1910-1917- toleraba las actividades de la diáspora venezolana en México contra el autoritarismo gomecista. Las enormes reservas petroleras en México y Venezuela que atraían la atención de las compañías inglesas y estadounidenses, convirtieron a ambos países en un tipo de polígono para la expansión de imperialismo. El entendimiento del hecho que los caminos de ambas naciones eran similares llevaba a las élites revolucionarias y/o nacionalistas de estos países a intentos de elaborar una actitud común, que a priori resultaba ser anti-estadounidense. El grave conflicto entre las autoridades mexicanas y los magnates petroleros de los EE.UU que gozaban del apoyo no declarado por parte de las autoridades de Washington, llevó a tensiones serias en las relaciones entre los dos países, obligando a México a buscar aliados potenciales.

La élite revolucionaria mexicana observaba con atención los acontecimientos en el país caribe fraterno. Fue absolutamente natural, porque Venezuela se consideraba como "la tercera frontera de México". Varios políticos e intelectuales mexicanos destacados, como José Vasconcelos y Carlos Pellicer, condenaban enérgicamente la dictadura de J.V.Gómez y desplegaron una campaña activa de solidaridad con los revolucionarios venezolanos. El 12 de octubre del 1920 Vasconcelos -quien mantenía contactos con los exiliados residentes en Nueva York y sabía sobre las declaraciones antigomecistas de la Junta Revolucionaria Venezolana en La Habana- expresó a grandes rasgos la actitud de México respecto al asunto venezolano. La Secretaría de Relaciones Exteriores de México, tras las protestas de Caracas, se deslindó de la declaración hecha por el famoso filósofo, sin embargo, las palabras de Vasconcelos fueron apoyadas de forma decidida por el Ministro de Guerra, Plutarco Elías Calles. La actitud de Vasconcelos fue absolutamente clara: el gobierno revolucionario y nacionalista de México no podía observar tranquilamente como actuaba el régimen oligárquico, despótico y tiránico. Más tarde, en 1924, Vasconcelos hasta tildó al líder venezolano como un 'cerdo humano' protegido por las "compañías extranjeras que explotan al país". ${ }^{14}$ Gómez ordenó entonces el retiro de la representación diplomática venezolana de la capital mexicana.

La posición de la élite política mexicana estaba dirigida al acercamiento con la diáspora antigomecista venezolana para involucrarla en una alianza antiimperialista $y$, obviamente,

\footnotetext{
${ }^{13}$ Lidia V. Pegusheva. América Latina: “panamericanismo” en el movimiento obrero (Moscú: Nauka, 1974) 46.

${ }^{14}$ Vasconcelos, José. Discursos 1920-1950 (México: Ediciones Botas, 1950) 55-61; Ricardo Melgar Bao, "El exilio venezolano en México", Memoria, 110 (1998): 39. Véase también: Cobo, Lourdes, Estudio de las relaciones internacionales en Venezuela (Caracas: Ed. Ministerio de Relaciones Exteriores, 1982).
} 
Víctor Jeifets y Lazar Jeifets, La inserción internacional de la izquierda comunista anti-gomecista en el exilio venezolano, primeros años - The international insertion of the Communist Left-Wing anti-Gómez tendency of the Venezuelan exiles, the first years, Revista Izquierdas, 25, octubre 2015, IDEA-USACH, ISSN 0718-5049, pp. $1-28$

coincidía en este aspecto con la actitud de la Comintern que luchaba por organizar un bloque antimperialista bajo su propia égida en la mitad de la década de 1920.

En 1920-1921 el gobierno de México concedió asilo a varios venezolanos, incluso al exgobernador de Caracas, Carlos de León, que había participado en el alzamiento contra la dictadura de J.V.Gómez en el año 1919, y a Miguel Zúñiga Cisneros, que había sido representante de la Federación de Estudiantes de Venezuela, FEV, en el Primer Congreso Nacional de Estudiantes en México convocado por Vasconcelos. El ex-comunista mexicano Felipe Carrillo Puerto, en aquel entonces gobernador del estado de Yucatán, nombró a De León como su secretario especial y puso a su disposición un arsenal para preparar la expedición armada contra J.V.Gómez. ${ }^{15}$ La idea de la lucha armada contra la dictadura encajaba muy bien en la lógica de la revolución mexicana y el pensamiento de varios intelectuales latinoamericanos, así como en la del movimiento obrero en general, es decir, estaban de acuerdo con que el régimen oligárquico debería ser derrocado por la fuerza. Mientras tanto, los llamados a ejercer presión pacífica, algo típico del presidente estadounidense Woodrow Wilson (1913-1921), no podían ser percibidos sino como una abierta injerencia imperialista para apoyar el poder del odiado líder.

En 1923-1924, los hermanos Gustavo y Eduardo Machado, que ya eran conocidos como activistas del comunismo internacional desde su estancia en Cuba, además de convencidos antigomecistas, recibieron de C. de León la información de que el presidente mexicano Álvaro Obregón (1920-1924) había autorizado el otorgamiento de armas a los firmantes del llamado "Pacto Revolucionario de Angelita", que querían desembarcar en Venezuela. Su sucesor en la silla presidencial, Plutarco E. Calles (1924-1928), también apoyaba al sector radical del exilio venezolano. ${ }^{16}$

La llegada de los hermanos Machado y de Salvador de la Plaza a México dio un nuevo impulso a la actividad política del exilio venezolano en aquel país. Junto con Zúñiga y De León fundaron en 1926 el Partido Revolucionario Venezolano -que prontamente estableció relaciones con la Comintern - con el objeto de formar una gran alianza contra Gómez. Para los exiliados venezolanos involucrados seriamente en las actividades de la sección mexicana de la III Internacional, el proyecto del PRV se convirtió en una nueva oportunidad de ampliar sus relaciones de cooperación con la élite política de México, abriendo nuevas perspectivas de inserción en las filas del comunismo internacional.

El programa del PRV poseía una visión internacionalista bastante amplia. Esto se explicaba en gran medida por la conformación de los militantes antigomecistas residentes en diferentes países de América Latina, ${ }^{17}$ convencidos de la necesidad de resistir al

\footnotetext{
${ }^{15}$ García Ponce 67.

${ }^{16}$ El gobierno de México estaba dispuesto a entregar a los exiliados venezolanos armas por el monto de más de 25 mil dólares y prometía entregarles, además, 7 mil dólares para los gastos de movilización después de conseguir el barco para la expedición. El jefe del Estado Mayor de la Presidencia mexicana, el general Álvarez, notificó de esto a los exiliados venezolanos residentes en La Habana. "G. Machado al Comité Ejecutivo de la Internacional Comunista”. RGASPI, F. 495, inv.107, exp. 3, f. 58. Obviamente, A. Obregón perseguía sus propios objetivos queriendo echar de México a los generales villistas, a los cuales los exiliados antigomecistas querrían hacer participar en la expedición.

${ }^{17}$ Entre los fundadores y militantes del partido se destacaban los venezolanos J.A. Silva Márquez, Pedro Brito y Ricardo A. Martínez, Alonso Ramírez y un grupo de generales antigomecistas, el cubano Julio Antonio
} 
Víctor Jeifets y Lazar Jeifets, La inserción internacional de la izquierda comunista anti-gomecista en el exilio venezolano, primeros años - The international insertion of the Communist Left-Wing anti-Gómez tendency of the Venezuelan exiles, the first years, Revista Izquierdas, 25, octubre 2015, IDEA-USACH, ISSN 0718-5049, pp. $1-28$

imperialismo y emprender la lucha en contra de las dictaduras sin fijarse en las fronteras nacionales. El partido estaba dispuesto a conseguir el derrocamiento del régimen de J.V.Gómez, planteando al mismo tiempo el objetivo de acabar con el 'caudillismo' y los 'politicastros' en el resto del mundo. ${ }^{18}$ Tal plataforma podría convertirse efectivamente en una base para la unión de los diversos círculos del exilio venezolano.

El programa de transformaciones sociales propuestas por el PRV no era tan radical, más bien se trataba de un compromiso para formar un frente antigomecista. En la esfera agrícola se planteaba la confiscación de la propiedad del "tirano y de su pandilla", a diferencia de los comunistas, los "PRVistas" no demandaban realizar una reforma agraria a gran escala y liquidar el dominio de los terratenientes. El partido proclamó, además, su intención de acabar con la discriminación racial y resolver las demandas obreras por medio de la 'liberación de las masas laboriosas de la arbitrariedad de los capitalistas" y el desarrollo de sindicatos. Los dirigentes del PRV arremetían enérgicamente en contra del capital extranjero y su intervención en los asuntos interiores de las 'naciones débiles', exigiendo establecer condiciones de igualdad para los inversionistas nacionales y extranjeros. ${ }^{19}$

El partido prometía transformaciones profundas en el ejército para convertirlo defensor del proyecto popular encabezado por 'los revolucionarios puros y francos, miembros del PRV'. Respecto a la lucha contra el problema de corrupción en Venezuela, los dirigentes proponían recetas con cierta dosis de "manilovismo", ${ }^{20}$ es decir, involucrar en la política a "los hombres de bien" y hacer que "TODOS los venezolanos puedan darse buena vida y que la nación sea fuerte". ${ }^{21}$ Proponían, además, delegar la representación de diferentes grupos profesionales a los organismos del poder para controlarlos, haciendo una clara alusión al sistema de los Diputados Obreros en la URSS (los Soviets), sin embargo, el programa no decía una sola palabra sobre la experiencia soviética. En el sentido

Mella, los mexicanos Diego Rivera y David Alfaro Siqueiros, el panameño Diógenes de la Rosa, el salvadoreño Agustín Farabundo Martí. Amalia Allen, la esposa del primer Secretario General del Partido Comunista Mexicano, José Allen, fue miembro de la célula del PRV en la Ciudad de México. Las secciones del PRV actuaban en Venezuela, Colombia, EE.UU., Panamá, Francia, Puerto-Rico, Cuba, Trinidad y Curazao. "Partido Revolucionario Venezolano. Credencial del compañero Salvador de la Plaza", México, D.F., 8 de octubre de 1927. RGASPI, F. 495, inv.107, exp. 3, f. 53. Los documentos encontrados en los archivos, no dejan ver claro cuántos militantes activos había reclutado el PRV. Como ejemplo, la sección parisina en 1930 contaba con apenas 9 miembros activos y 3 simpatizantes. - "A los compañeros miembros del CEC y a los miembros de todas las Locales del Partido Revolucionario Venezolano", Paris, 26 de Febrero de 1930. RGASPI, inv. 107, exp. 16, f. 4. Notemos, al mismo tiempo, que la mayoría de los Partidos Comunistas latinoamericanos en aquel entonces tampoco podían presumir de carácter masivo.

18 "Programme du Parti Révolutionnaire Venezuelienne. Explication de quelques uns des points des principes fondamentaux de la Revolution Venezuelienne objet du Parti Revolutionnaire Venezuelien. (P.R.V.)", Mexique, 31 mai 1927. RGASPI, f. 495, inv. 107, exp. 3, f. 40.

19 "Programa de Gobierno del Partido Revolucionario Venezolano, de acuerdo con los siguientes principios", México, 5 de mayo de 1927. Archivo de Salvador de la Plaza, Documentos referentes a Salvador de la Plaza. -http://salvadordelaplaza.faces.ula.ve/visual.php?volumen id=1507\&revista id=13; "Manifiesto del Partido Revolucionario Venezolano". Archivo de Salvador de la Plaza, Documentos referentes a Salvador de la Plaza. - http://salvadordelaplaza.faces.ula.ve/visual.php?volumen_id=1506\&revista_id=13

${ }^{20}$ La beatitud de Manilov, uno de los personajes de la obra del escritor ruso Nikolai Gógol “Almas Muertas". Se usa para referirse al arbitrismo, la mansedumbre insubsistente y la inactividad.

21 «Programme du Parti... », Ff. 44-45. 
Víctor Jeifets y Lazar Jeifets, La inserción internacional de la izquierda comunista anti-gomecista en el exilio venezolano, primeros años - The international insertion of the Communist Left-Wing anti-Gómez tendency of the Venezuelan exiles, the first years, Revista Izquierdas, 25, octubre 2015, IDEA-USACH, ISSN 0718-5049, pp. $1-28$

organizativo el PRV aspiraba aumentar la cantidad de sus militantes en el extranjero con su infiltración posterior en el territorio venezolano.

Los fundadores del partido prometían formar en Venezuela "un gobierno de principios y no de un solo jefe", acabar con "el dominio de individuos y poner en su lugar el dominio de las ideas". ${ }^{22}$ Aún el análisis superficial del programa del PRV (publicado en México el 1 de junio de 1927, firmado por Miguel Zúñiga Cisneros y el Secretario General, Gustavo Machado) demuestra que no era comunista, sino más bien una asociación revolucionaria con el programa antiimperialista y demócratico.

Sin embargo, el PRV resultaba ser la fachada legal para otro organismo, y muchos militantes del partido ni siquiera se daban por enterados. Los comunistas que figuraban entre los fundadores del PRV entendían que varios de sus aliados antigomecistas no estarían de acuerdo con la idea de extender la revolución mundial al territorio venezolano. Consecuentemente, crearon dentro del PRV el Grupo Continental Revolucionario (GCR) como una estructura secreta. Los objetivos y tareas del Grupo diferían drásticamente de lo expuesto en el programa del PRV. El memorando del GCR declaraba necesidad de aprovechar la situación tras una eventual victoria del alzamiento armado "que estaba preparándose en el momento actual", para alcanzar "el triunfo del comunismo en América". Estos objetivos se convirtieron en el programa máximo del sector radical del exilio venezolano. El GCR aspiraba a despertar el interés en "todos los elementos avanzados que comprendan que la Revolución Social <...> necesita que el proletariado conquiste el poder en uno de los países de este Continente; para que de esta manera se pueda contar con los elementos de agitación y refugio que hagan posible la lucha en los otros". ${ }^{23}$ Venezuela fue considerada como la futura base de la revolución continental y la lucha por el establecimiento de la dictadura del proletariado.

Los líderes del Grupo tomaban en cuenta "sólo la táctica que imponían las circunstancias, ya que el programa ideológico fue el del Partido Comunista". Estimaban necesario mantener en secreto sus objetivos tras la victoria del alzamiento armado para asegurar la participación tanto del mismo GCR como de las masas amplias, y al mismo tiempo para no dar al capital extranjero un motivo para su intervención. Mientras tanto, los integrantes del Grupo estaban dispuestos formar un frente único con todas las organizaciones, sin importar cual fuera su orientación social. ${ }^{24}$

En aquel período los hermanos Machado y Salvador de la Plaza no eran los únicos revolucionarios que pensaban en escala continental, varios personajes destacados del movimiento revolucionario latinoamericano compartían su punto de vista. Así, el Secretario General del Comité Continental de LADLA, el cubano Julio Antonio Mella, planteaba la necesidad de una expedición armada a Cuba junto con la Unión Nacionalista (UN). El fundador de la Alianza Popular Revolucionaria Americana (APRA), el peruano Víctor Raúl Haya de la Torre, propuso a la Comintern un proyecto de acciones revolucionarias que

\footnotetext{
22 "Programme du Parti...", f. 46.

23 “Grupo Continental Revolucionario. Salvador de la Plaza, Secretario General”, México, 1926. RGASPI, f. 495, inv.107, exp. 3, f. 35.

24 “Grupo Continental Revolucionario....”, f. 46.
} 
Víctor Jeifets y Lazar Jeifets, La inserción internacional de la izquierda comunista anti-gomecista en el exilio venezolano, primeros años - The international insertion of the Communist Left-Wing anti-Gómez tendency of the Venezuelan exiles, the first years, Revista Izquierdas, 25, octubre 2015, IDEA-USACH, ISSN 0718-5049, pp. $1-28$

empezarían en Perú y luego abarcarían a toda América Latina. ${ }^{25}$ Los dirigentes del Partido Comunista de México (PCM) fueron informados desde el principio sobre el programa de los exiliados venezolanos (tanto de forma oficial, como secreta) y no dudaron en prestarles su apoyo. ${ }^{26}$

\section{El PRV en la órbita del comunismo internacional}

Los delegados de la Comintern en México también fueron enterados sobre los planes de PRV y GRC. El Representante Plenipotenciario de la URSS y a la vez representante del Comité Ejecutivo de la Comintern, Stanislav Pestkovky, mantenía relaciones amistosas con los exiliados revolucionarios latinoamericanos, entre quienes se destacaba el cubano Mella, los venezolanos De León, Zúñiga Cisneros, G. Machado y De la Plaza. Todos ellos visitaban la misión diplomática soviética de manera regular. ${ }^{27}$ Durante estas citas se planteaban las posibilidades de cooperación práctica para la preparación de una expedición armada a Venezuela. Según el diario de Pestkovsky, el embajador soviético apoyaba decididamente el plan. Su lógica era simple: el régimen tiránico de Gómez mantenía buenas relaciones con los EE. UU. Consecuentemente, la presencia de la oposición activa y enérgica a este régimen fuera de Venezuela crearía una base para el despliegue del movimiento antidictatorial y antiimperialista continental, por lo que no se debía perder la oportunidad.

La actitud de la Comintern respecto al movimiento revolucionario venezolano en gran medida se formaba en base a las opiniones de los delegados de la Internacional en América Latina. Obviamente, los conceptos de otros enviados de la Comintern que visitaban México en aquel período, Mijaíl Grollman (“Oswald”) y EdgarWoog (“Stirner”) no discordaban del punto de la vista del Representante Plenipotenciario. ${ }^{28}$ Al contrario, el emisario del CEIC Boris Mijailov ("Williams", "Raimon"), que visitó América del Sur en 1926-1927, tenía una opinión más pesimista sobre las perspectivas del movimiento revolucionario venezolano. Aunque iba a emprender viajes al Perú, Chile, Bolivia y Uruguay, no planeaba ir a Colombia, Ecuador y Venezuela, porque allí "no había casi nada, apenas algunos grupos simpatizantes mal formados". ${ }^{29}$ Las estimaciones hechas por Mijailov demuestran claramente lo poco que sabía sobre el movimiento obrero y comunista en varias naciones sudamericanas, pero al mismo tiempo, sus informes también impactaban las decisiones tomadas en Moscú. Dos años después, la enorme huelga bananera en Colombia liderada por el Partido Socialista Revolucionario se convertiría en uno de los asuntos claves para todos

\footnotetext{
${ }^{25}$ Lazar Jeifets y Víctor Jeifets, “Haya de la Torre, ¿un comunista latinoamericano?”, Historia 6 (2011): 1415.

26 “Salvador de la Plaza a Rafael Carrillo", México, 1 de abril de 1926. RGASPI, F. 495, inv.107, exp. 3 , f. 3.

27 "Diario del representante plenipotenciario", sin fecha. Archivo de Política Exterior de la Federación Rusa (AVPRF), Moscú. Departamento Mexicano, F. 0110, inv. 6, exp. 1, carpeta 101, f. 73.

${ }^{28}$ En uno de sus informes a la Comintern Stirner escribió sobre las conversaciones reiteradas con C. de León sobre el movimiento revolucionario venezolano (obviamente, con los comunistas del PRV, G. Machado y S. de la Plaza también). "Carta del representante de la Comintern en México, A. Stirner, al jefe del Secretariado Latino J. Humbert-Droz", 27 de mayo de 1927, f. 76.

29 “Carta de Raymond [B. Mijailov]”, julio de 1926. RGASPI, F. 495, inv.19, exp. 182, f. 8.
} 
Víctor Jeifets y Lazar Jeifets, La inserción internacional de la izquierda comunista anti-gomecista en el exilio venezolano, primeros años - The international insertion of the Communist Left-Wing anti-Gómez tendency of the Venezuelan exiles, the first years, Revista Izquierdas, 25, octubre 2015, IDEA-USACH, ISSN 0718-5049, pp. $1-28$

los comunistas latinoamericanos, y los comunistas venezolanos y ecuatorianos también comenzaron demostrar buenas perspectivas. Los pronósticos del emisario de la Comintern fueron errados. ${ }^{30}$

En el verano de 1926 los dirigentes del GCR autorizaron a Machado para tramitar en Europa la fundación de secciones "conforme al Programa secreto de acción" y a realizar otros puntos del programa para "alcanzar nuestros objetivos". El objetivo final de la misión de Machado fue el establecimiento de "relaciones de fraternidad" entre el gobierno de la URSS y el gobierno que iba a ser creado en Venezuela tras el triunfo eventual de la revolución antigomecista. Además, Machado representaba al GCR "en el asunto de cómo realizar lo que habíamos hablado recientemente con Ud.". ${ }^{31}$ Esta frase era muy disimulada, pero al consignatario de la carta, EdgarWoog (uno de los encargados por los asuntos latinoamericanos en la Comintern), no hacía falta explicarle de qué se trataba y lo que no se podía escribir ni en una carta más confidencial.

Machado envió al Comité Ejecutivo de la Comintern el memorando sobre los planes del alzamiento armado planeado por los PRV y GCR solicitando ayuda urgente a los insurgentes: "Uds. Compañeros, directores en la actualidad del movimiento mundial de liberación de los oprimidos $<\ldots>$ seguramente han apreciado [la importancia de nuestra acción ]". 32

La situación de aquel entonces no favorecía a los futuros insurgentes. Los representantes del gobierno mexicano que les habían mostrado simpatía, ahora se sentían nerviosos porque los venezolanos no lograban conseguir un barco para transportar las armas regaladas que les habían proporcionado. Machado subrayaba que la influencia de los comunistas dentro del PRV podía aumentar a condición de que fueran ellos quienes consiguieran el dinero necesario. C. de León otorgó a Machado poderes especiales para negociar este asunto en Rusia. $^{33}$

El emisario del PRV y GCR pidió al CEIC designar al experto en asuntos militares y representante político "para que ellos desde el principio participaran en el desarrollo del movimiento mencionado" y pudieran unirse a él en París para viajar juntos a México. Insistiendo en la urgencia del apoyo financiero de parte de la Comintern, el venezolano afirmaba: "La falta de 15 mil [dólares] en estos momentos representará una pérdida de 250 mil [dólares] para la Revolución en América Latina, aparte de la oportunidad especialísima

\footnotetext{
${ }^{30}$ Lazar Jeifets y Víctor Jeifets, "El giro a la izquierda en América Latina y el nacimiento del nuevo bolivarianismo: las tradiciones de la Komintern y la actualidad", Revista CS, 7 (2009): 195-212; Víctor Jeifets y Lazar Jeifets, "Los orígenes del Partido Comunista del Ecuador y la Tercera Internacional", Izquierdas, 1.6 (2010).

31 “Grupo Continental Revolucionario...”, 23 de junio de 1926. RGASPI, F. 495, inv.107, exp. 3, f. 16. G. Machado escribía más tarde que su misión había sido planificada "conforme a la consultación preliminar con el enviado plenipotenciario Pestkovsky". "Autobiografía de G. Machado", 1952. RGASPI, F. 495, inv. 200, exp. 16 (Expediente personal de G. Machado.). ff. 161-162; "Salvador de la Plaza al Camarada Alfredo Stirner”, México, 23 de junio de 1926. RGASPI. F.495, inv. 197, exp. 3, f. 15.

32 “G. Machado al Comité Ejecutivo de la Internacional Comunista”, ... f.58.

${ }^{33}$ Machado notaba que "debido a su vida anterior, [De León] era la garantía de cumplimiento del programa de la Revolución”, obviamente sobreentendiendo la pasada pertenencia del líder del exilio a las elites venezolanas.
} 
Víctor Jeifets y Lazar Jeifets, La inserción internacional de la izquierda comunista anti-gomecista en el exilio venezolano, primeros años - The international insertion of the Communist Left-Wing anti-Gómez tendency of the Venezuelan exiles, the first years, Revista Izquierdas, 25, octubre 2015, IDEA-USACH, ISSN 0718-5049, pp. $1-28$

que no aprovechemos y otras consecuencias que Uds. pueden proveer". ${ }^{34}$ Defendía el punto de vista del exilio venezolano radical en las sesiones de una comisión especial y hasta (según él) en la sesión del Comité Ejecutivo de la Comintern. ${ }^{35}$ Según Machado recordaba más tarde, "todos aquellos proyectos fueron percibidos como unos 'pronunciamientos' sin base social en el interior", por lo que Moscú recomendó a los revolucionarios penetrar al territorio venezolano y construir el partido revolucionario 'sobre la base de la clase obrera, campesinos y ciudadanos descontentos'. La Comintern dejó claro que no habría ninguna transformación seria sin la existencia de un Partido Comunista 'arraigado en las masas laboriosas del país'. ${ }^{36}$ El momento definitivo en la formación de tal aproximación fue la actitud categórica del Comisariado del Pueblo para los Asuntos Exteriores de la URSS expresada por el vice-comisario, Máxim Litvinov quien informó al Secretariado del CEIC sobre la falta de posibilidades para entablar relaciones oficiales con los representantes de los exiliados revolucionarios venezolanos. ${ }^{37}$

Al parecer, Gustavo Machado no entendió que era la respuesta final y supuso que el Estado Mayor de la revolución mundial podría actuar de manera autónoma del gobierno soviético. Intentó cambiar las circunstancias y, al irse de Moscú, escribió otra vez al CEIC sobre las dificultades que habían sido creadas para el 'gobierno revolucionario de Venezuela' por el Comisariado Popular para los Asuntos Exteriores de la URSS: "En ningún momento se pensó en que se me recibiese oficialmente ni en que se reconociese actualmente por la U.R.S.S. el Gbno. Revolucionario que represento. Se trataba exclusivamente de conversar extra-oficialmente de las relaciones futuras, cuando el Gbno. Revolucionario estuviese en Venezuela; de la oportunidad y del momento en que el reconocimiento por la U.R.S.S. debe efectuarse y ser conocido públicamente, para que este hecho no comprometa la apariencia democrática liberal avanzada a que nos obliga en los primeros meses el poder del Imperialismo Yanqui'. El enviado extraordinario del 'gobierno revolucionario' de Venezuela fue desalentado por la actitud obstruccionista de las autoridades soviéticas. A los líderes del exilio radical venezolano no les cabía en la menta el hecho de que la Comintern y "la patria de todos los proletarios del mundo" podrían reaccionar negativamente a su ruego de ayuda. En una expresión de deseos poco realista, Machado informó a De León que la actitud de la URSS fue amistosa y que el reconocimiento iba a ocurrir en el momento debido. ${ }^{38}$

Woog, que en aquel tiempo estaba en México, no compartía la posición tomada por el Comisariado del Pueblo y por el CEIC. Tras el fracaso de la misión de Machado, el suizo

\footnotetext{
34 "G. Machado al Comité Ejecutivo de la Internacional Comunista", f. 59. El monto de 15 mil dólares era necesario para comprar el barco.

${ }^{35}$ Machado se refirió a ese episodio en su autobiografía escrita en diciembre de 1952. A lo mejor, confundía el CEIC con el Lender-secretariado del CEIC. La convocatoria de la sesión del CEIC para la discusión de este asunto parece poco probable.

36 "G. Machado al Comité Ejecutivo de la Internacional Comunista", f. 59. Al parecer, el líder del PCV podía equivocarse en lo que respecta a las declaraciones de Moscú, extrapolando la evaluaciones más tardías de la Comintern sobre la actividad del PRV y la situación del año 1926.

37 "La carta del vice-comisario popular de asuntos exteriores de la URSS, Máxim Litvinov, al Secretariado del CEIC", 3 de septiembre de 1926. RGASPI. F. 495, inv. 200, exp. 16 (Carpeta personal de G. Machado), f. 220.

38 “G. Machado al Comité Ejecutivo de la Internacional Comunista”, ff. 58-59.
} 
Víctor Jeifets y Lazar Jeifets, La inserción internacional de la izquierda comunista anti-gomecista en el exilio venezolano, primeros años - The international insertion of the Communist Left-Wing anti-Gómez tendency of the Venezuelan exiles, the first years, Revista Izquierdas, 25, octubre 2015, IDEA-USACH, ISSN 0718-5049, pp. $1-28$

prometió a C. de León informar a los dirigentes de la Comintern sobre las necesidades de los revolucionarios venezolanos, pero al mismo tiempo le aconsejó que de León mismo viajara a Moscú y contara sobre la situación. Según evaluación hecha por Woog, "los camaradas venezolanos estaban organizados mucho mejor que aquella gente que dirigía el movimiento liberal en Nicaragua, y sus perspectivas de resistir a la intervención americana eran mucho mayores". 39 Pero la opinión de Woog tampoco logró impresionar a los burócratas de la revolución mundial en Moscú. Los dirigentes superiores de la Comintern y de la política exterior de la URSS no renunciaron a su decisión previa.

A finales del 1926 Moscú recibió otro pedido de apoyo, esta vez enviado por el presidente de la UOV, Flores Cabrera, quien se dirigió directamente al Secretario General del CC del Partido Comunista Pan-Soviético, José Stalin. Poco antes de aparecer esta carta, el periódico estadounidense "New York Evening Enquirer" había informado sobre la posibilidad de revisar las concesiones petroleras como consecuencia de la enfermedad del general Gómez y el caos probable que este hecho ocasionaría. F. Cabrera escribía a Stalin:

Los vampiros del gran capital y los chanchos petroleros están preocupados: su juego podrido está en el centro de la atención. Están contrayéndose porque no están acostumbrados a que les molesten. $<\ldots>$

La caída del capital imperialista en Venezuela está cerca <...>. Todas las concesiones petroleras fueron expedidas directamente por el jefe del estado y, en consecuencia, son ilegales desde el punto de vista de la legislación de Venezuela y van a ser revisadas de todos modos. <...> Los chanchos serán exilados. ¡Y este día del juicio final Simón Bolívar va a regresar a Caracas! $!^{40}$

A las frases enfáticas revolucionarias les siguió el pedido concreto: prestar el apoyo material a la UOV para que pudiera influir en los acontecimientos de Venezuela. F. Cabrera declaró francamente:

Estamos obligados a dejar nuestras actividades debido a la falta de recursos. $<\ldots>$ en caso de disponer de financiamiento <...> la Unión Obrera Venezolana <...> podría regresar a Venezuela y convertirse en un poder igual de influyente como la CROM [Confederación Regional Obrera Mexicana]. Ustedes ayudan a los chinos en su lucha contra los atrincherados capitalistas imperialistas europeos y americanos. ¿Acaso nosotros, los hijos de Bolívar, no merecemos esto? $^{41}$

Ambas invocaciones de los revolucionarios venezolanos fueron rechazadas. Los motivos por los cuales Moscú prescindió el pedido del PRV se encuentran en la difícil situación internacional. Cuando las tentativas de organizar los alzamientos armados comunistas en Alemania y en los Balcanes habían fracasado, y la ayuda soviética a la revolución china no llevó a los resultados esperados, el apoyo a los revolucionarios en un lejano país

\footnotetext{
39 "La carta del representante de la Comintern en México, A. Stirner, al jefe del Secretariado Latino J. Humbert-Droz", 27 de mayo de 1927, f. 76.

40 "Flores Cabrera, the President of the Venezuelan Workers' Union to Mr. Joseph Stalin, the Secretary of the Central Committee", November, 11, of 1926. RGASPI, f. 534, inv. 7, exp. 95, ff. 1-3.

41 "Flores Cabrera, the President of the Venezuelan Workers' Union to Mr. Joseph Stalin, the Secretary of the Central Committee", November, 11, of 1926. RGASPI, f. 534, inv. 7, exp. 95, ff. 1-3.
} 
Víctor Jeifets y Lazar Jeifets, La inserción internacional de la izquierda comunista anti-gomecista en el exilio venezolano, primeros años - The international insertion of the Communist Left-Wing anti-Gómez tendency of the Venezuelan exiles, the first years, Revista Izquierdas, 25, octubre 2015, IDEA-USACH, ISSN 0718-5049, pp. $1-28$

latinoamericano parecía una aventura que no podía ser favorable para la revolución proletaria mundial. Además, los dirigentes de la III Internacional estaban aún bajo la impresión del fracaso del plan de revolución panamericana en México a principios de los años veinte. De lo que tenían miedo en el cuartel general de la Comintern era de la pérdida de hegemonía del partido del proletariado en la revolución, el derrumbe de las ideas de la revolución socialista en toda la ideología democrática del movimiento anti-dictatorial, y la degeneración de sus partidarios en el caso de ingresar al gobierno como parte de una amplia coalición. Esos temores no eran absolutamente infundados, pues en América Latina el grado de fidelidad a la Comintern de los adeptos a la revolución mundial era bastante condicional. El comunismo era más un sueño que una ideología, lo mismo que hoy para la Venezuela chavista y post-chavista. El CEIC no pudo contar con que la lealtad a Moscú se mantendría después del triunfo de la revolución. Por eso mismo sus miembros no consideraron posible derrocar a los regímenes tiránicos por fuerzas que no estaban bajo control completo de la Comintern, proponiendo la revolución socialista para un futuro lejano. Ni el partido comunista mundial ni el CC del PC de la URSS, iban a "cazar cien pájaros volando". Aún peor, la referencia a la posibilidad de transformar la UOV en el análogo venezolano de la CROM les puso en alerta, porque las relaciones entre Moscú y la central sindical reformista mexicana eran malas hasta más no poder.

El plan del PRV y GCR de organizar una acción armada contra J.V.Gómez con el apoyo de los gobiernos de México y de la URSS colapsó. El presidente P. E. Calles rechazó el préstamo de armas antes prometidas por su antecesor. El interés de la élite gobernante mexicana hacia los acontecimientos venezolanos obviamente se debilitó, y los exiliados venezolanos activaron las búsquedas de armas y municiones en otras partes del mundo. Intentaron comprar un barco en la República Dominicana, pero fracasaron, tras lo cual las autoridades mexicanas abandonaron definitivamente cualquier intento por ayudarles. ${ }^{42} \mathrm{~A}$ partir de este momento los dirigentes del GCR aumentaron su actividad dentro del Partido Comunista de México, contribuyendo, en particular, al desarrollo de las estructuras de la Liga Antimperialista de las Américas. S. de la Plaza fue nombrado Secretario General del Comité Organizador Continental de la Liga. Gustavo Machado, a su vez, representaba a la sección nicaragüense de la Liga y al Partido Socialista Revolucionario de Colombia en el Congreso Antiimperialista en Bruselas (1927) y luego se dirigió a las montañas de Segovia como delegado del Comité “iManos Fuera de Nicaragua!” (MAFUENIC) en el Estado Mayor del Ejército de Defensa de la Soberanía Nacional, EDSN, dirigido por Augusto César Sandino. Y el "general de la gente libre", como lo llamaban, a su turno nombró al comunista venezolano como su representante en México. Machado recorre toda Centroamérica (Guatemala, Honduras, El Salvador) haciendo propaganda de la causa sandinista, antimperialista y comunista, establece contactos con el poeta hondureño Froilán Turcios, director de la revista "Ariel" y propagandista fervoroso del sandinismo. Otro militante del PRV, Carlos Aponte, era asistente de Sandino, y luego recibió el grado de coronel del EDSN.

Sin embargo, el viaje a Moscú emprendido por Machado, dio impulso al desarrollo de los contactos entre el exilio comunista venezolano y la Comintern. S. de la Plaza y Carmen

42 “Autobiografía de G. Machado”, 1952, f. 162; García Ponce 76. 
Víctor Jeifets y Lazar Jeifets, La inserción internacional de la izquierda comunista anti-gomecista en el exilio venezolano, primeros años - The international insertion of the Communist Left-Wing anti-Gómez tendency of the Venezuelan exiles, the first years, Revista Izquierdas, 25, octubre 2015, IDEA-USACH, ISSN 0718-5049, pp. $1-28$

Fortul participaron en el Congreso de Amigos de la URSS celebrado dentro de los marcos del X aniversario de la Gran Revolución Socialista de Octubre, y fueron elegidos para su Presídium. Aunque en la lista de los delegados De la Plaza fue nombrada como representante de Colombia, esto fue condicionado por motivos de propaganda. Efectivamente, había llegado a Moscú con la credencial expedida por el CEC del PRV para "discutir los asuntos de organización", participaba en la discusión del asunto mexicano en el CEIC, presentó su informe sobre Venezuela en la sesión del Buró Ejecutivo de la Internacional Sindical Roja, fue elegido como miembro del Comité de Preparación de la Conferencia Sindical Latinoamericana y, por último, fue nombrado miembro del Comité de Preparación del Congreso Sindical en Montevideo, como representante de Venezuela. Se suponía que De la Plaza iba a participar en el VI Congreso de la Comintern como delegado del PRV. Sin embargo, no podía quedarse más en Moscú y regresó a México donde en 1928 hizo un informe sobre el movimiento antiimperialista en la V Conferencia Nacional del PCM, fue elegido como miembro del CC, tesorero del CC del PCM y en junio de mismo año representaba a PCM en las sesiones de la Comisión Política del W (C) PA, en las que se discutía el conflicto entre el Comité Continental de LADLA y el Secretario de su sección norteamericana, Manuel Gómez.

Otro venezolano con voz consultiva en el VI Congreso mundial de la Comintern, fue Ricardo A. Martínez, quien era miembro del W(C) PA y del PRV. Su intervención durante la discusión sobre el movimiento revolucionario en los países coloniales y semicoloniales tuvo en carácter general, sin tratar los pormenores de la revolución en su propio país y la actividad del PRV. Él mismo representaba a Venezuela en la Conferencia Sindical Latinoamericana (Moscú, abril de 1928) y en el V Congreso de la ISR donde fue elegido como miembro del Buró Ejecutivo del Consejo Central de la Internacional Sindical Roja, y luego fue nombrado jefe de su sección latinoamericana. ${ }^{43}$ Carmen Fortoul también se quedó en la capital soviética para ingresar como estudiante en la Escuela Leninista Internacional según la cuota de los comunistas venezolanos.

\section{El "camino garibaldino" de los comunistas venezolanos Vs. el concepto del partido proletario}

El Comité Continental de LADLA controlado por el PCM tenía sus propios motivos para apoyar activamente al exilio antigomecista. Los dirigentes de la Liga y del Partido Comunista de México entendían perfectamente tanto la heterogeneidad ideológica de la oposición antidictatorial como el hecho que los comunistas no fueron la fuerza dominante

\footnotetext{
43 Shestoi Vsemirnyi kongress Kommunisticheskogo Internatsionala. Stenograficheskii otchet. Vyp. 4 (Moscú: Gosizdat, 1928) 272-276; Izvestia [Moscú], 11o de oct. de 1927; Mezhdunarodnoie rabocheie dvizheniie, 15 (1928); "Partido Revolucionario Venezolano. Credencial del compañero Salvador de la Plaza", México, D.F., 8 de Octubre de 1927. RGASPI, F. 495, inv. 107, exp. 3, f. 53; "Lettre a Ricardo Martínez, Moscou, U.R.S.S», Barranquilla, Colombie, 20 juin 1928. RGASPI, inv. 107, exp. 8, f. 61; Lazar Jeifets, Víctor Jeifets y Peter Huber. La Internacional Comunista y América Latina, 1919-1943. Diccionario biográfico (Ginebra: Institut pour l'histoire du communisme, 2004) 198-200.
} 
Víctor Jeifets y Lazar Jeifets, La inserción internacional de la izquierda comunista anti-gomecista en el exilio venezolano, primeros años - The international insertion of the Communist Left-Wing anti-Gómez tendency of the Venezuelan exiles, the first years, Revista Izquierdas, 25, octubre 2015, IDEA-USACH, ISSN 0718-5049, pp. $1-28$

dentro de la oposición, aunque tenían cierta influencia. Los líderes de la LADLA inequívocamente evidenciaban a Moscú:

El ejemplo de Nicaragua demuestra que no es importante cual movimiento militar contra imperialismo es revolucionario. Una cooperación pequeña con el movimiento venezolano no sólo sería la lucha contra el imperialismo más grande del mundo y crearía la base para la actividad del movimiento antiimperialista y comunista en el Caribe $\langle\ldots\rangle$, sino ayudaría a la cooperación con México, $<\ldots>$ daría principio a los cambios en la política de este país respecto al país de los Soviets y al movimiento comunista en general. ${ }^{44}$ En caso de éxito de la expedición armada contra Gómez, surgiría el segundo centro, aparte de México, de despliegue de la "liberación nacional en contra del imperialismo. ${ }^{45}$

Aún más importante fue el hecho de que los comunistas mexicanos esperaban radicalizar la actitud de los gobernantes de México en su enfrentamiento con los EE.UU. y transformar la actitud del gobierno hacia el PCM de tolerante a benévola.

Pero la Comintern seguía rechazando la idea de una expedición armada al no ver las perspectivas de incorporación del "virtual gobierno revolucionario" de Venezuela en el movimiento antiimperialista continental. El Lender-Secretariado Latinoamericano del CEIC en su carta enviada a los comunistas miembros del PRV rechazó enfáticamente "el camino garibaldino" de derrocamiento de Gómez y la sustitución de la rebelión de masas por "el heroísmo individual". Este mensaje fue discutido en abril de1929 en una sesión especial del CC del PCM con la participación de los venezolanos que militaban en la sección mexicana de la III Internacional.

El CC del PCM hizo constar que de cara a las batallas revolucionarias en Venezuela los exiliados opositores a la dictadura gomecista eran capaces de ser "el factor decisivo" en los futuros acontecimientos, y desempeñaban un papel especial. Según la opinión del PCM, durante dos años el exilio radical venezolano consiguió superar la mentalidad feudal y "el fatalismo geográfico", es decir, la creencia que para derrocar a la dictadura habría que recibir el apoyo de los EE.UU. La resolución tomada era más que favorable para los comunistas dentro el PRV: "El PRV fue fundado por los comunistas venezolanos $<\ldots>$ por primera vez en la historia de Venezuela fue conformado el programa revolucionario que trataba de todos los asuntos importantes del movimiento revolucionario". ${ }^{46}$ Se notaba que la diáspora revolucionaria venezolana demostraba características anticaudillistas $\mathrm{y}$

\footnotetext{
${ }^{44}$ Mella, Julio Antonio, "L’information sur la Ligue Anti-Imperialiste Pan-Americain", Moscou, 25 de Mars du 1927. RGASPI, F. 495, inv. 18, exp. 604, f. 7.

${ }^{45}$ Venezuela no fue el único país donde los comunistas latinoamericanos planteaban la idea de una expedición armada para derrocar dictaduras. Una acción similar, con la sanción del CC del PCM, iba a emprender desde el territorio mexicano o estadounidense uno de los líderes de LADLA y del PCM, el cubano J.A. Mella, dispuesto a cooperar con los líderes del movimiento nacionalista, opositores al dictador Gerardo Machado. "La carta del CC de PCM al Secretariado Latino de Comintern", 14 de julio de 1928. RGASPI, F.495, inv. 108, exp. 84, ff. 42-42v; el mismo documento en: CEMOS. México, D.F. Colección PCM, caja 3, folio 17, f.1.

46 "Resolution of the Mexican Communist Party on the Venezuelan question on the basis of the letter addressed by the Latin American Secretariat of the C.I. to the Venezuelan communists", Mexico, D. F., April 16th 1929. RGASPI, f. 495, inv. 108, exp. 102, f. 1.
} 
Víctor Jeifets y Lazar Jeifets, La inserción internacional de la izquierda comunista anti-gomecista en el exilio venezolano, primeros años - The international insertion of the Communist Left-Wing anti-Gómez tendency of the Venezuelan exiles, the first years, Revista Izquierdas, 25, octubre 2015, IDEA-USACH, ISSN 0718-5049, pp. $1-28$

antiimperialistas, mientras que otros sectores del exilio incluían muchos caudillos y reformistas liberales así como "servidores". ${ }^{47}$

Estas dos tendencias estaban en una pugna eterna. En el verano de 1927 el general E. Arévalo Cedeño, conocido opositor al régimen de J.V. Gómez, uno de los fundadores del PRV y "El Comandante en Jefe de la Revolución", se distanció del partido al firmar en París un pacto con las agrupaciones del exilio venezolano y al publicar en el periódico de La Habana "Diario de la Marina" una carta abierta. Arévalo se solidarizó con la lucha contra "los canallas agitadores" y acuso a C. de León, G. Machado y S. de la Plaza de crear un partido "con tendencias bolsheviques y comunistas" para "desplegar en Venezuela una revolución que sería la copia exacta de las revoluciones escandalosas que vencieron hoy en Rusia y México". El general prohibió al PRV utilizar su nombre "porque la organización que está muy lejos de mi forma de pensar". Más tarde, Arévalo condenó al comunismo como "la gran mentira y el modo que van a emplear los sinvergüenzas y perezosos para realizar sus intenciones delictivas de vivir a cuenta de los engañados...". De igual forma arremetió en contra del aprismo considerándolo lacayo de la Rusia Soviética. Al declarar su pronto regreso a la lucha armada "contra la barbaridad que domina en Venezuela", ofreció a los líderes del PRV "un lugar en su campo para curarse de las ideas exóticas y nocivas, luchando por la libertad de Venezuela". ${ }^{48}$

En septiembre de 1927, la célula mexicana del PRV respondió con la expulsión de Arévalo del partido "por la traición de los principios básicos que él había jurado proteger hasta la muerte" y tildó al general como "protector de los intereses petroleros norteamericanos, vida y suerte de los actuales usurpadores del poder en Venezuela". ${ }^{49} \mathrm{La}$ ruptura con Arévalo Cedeño era muy dolorosa para el PRV tomando en cuenta su persistencia en la lucha antigomecista, así como sus capacidades para combatir militarmente al régimen dictatorial.

Sin embargo, para los comunistas mexicanos esto no era tan importante. Destacaron como un logro del PRV "la reorientación de los obreros hacia la lucha de clases contra imperialismo, hacia la protección de los comunistas". Según ellos, los comunistas constituían "la parte más activa y enérgica del exilio, siendo la única fuerza políticamente organizada tanto en Venezuela como fuera del país (subrayado por autores - V.J., L.J.)" ${ }^{50}$ Considerando necesaria la creación de la sección de la Comintern dentro de Venezuela, el PCM rechazaba "las tendencias liquidacionistas representadas por algunos camaradas en el partido comunista americano" que proponían acabar con el PRV e insistían

\footnotetext{
47 "Resolution of the Mexican Communist Party on the Venezuelan question on the basis of the letter addressed by the Latin American Secretariat of the C.I. to the Venezuelan communists", Mexico, D. F., April 16th 1929.RGASPI, F. 495, inv. 108, exp. 102, f. 2.

48 "La colonia venezolana. La Habana (Cuba).Carta Abierta". RGASPI, F. 495, inv. 107, exp. 10, f. 11; J. Sant Roz. Conozca quién fue el gran General Emilio Arévalo Cedeño // http://www.aporrea.org/actualidad/a40327.html

49 "Resolution d'expulsion du Général Arevalo C. du Parti Revolutionnaire Vénézulien". RGASPI, f. 495, inv. 107, exp. 3, f. 50.

50 "Resolution of the Mexican Communist Party on the Venezuelan question on the basis of the letter addressed by the Latin American Secretariat of the C.I. to the Venezuelan communists", Mexico, D. F., April 16th 1929. RGASPI, F. 495, inv. 108, exp. 102, f. 1.
} 
Víctor Jeifets y Lazar Jeifets, La inserción internacional de la izquierda comunista anti-gomecista en el exilio venezolano, primeros años - The international insertion of the Communist Left-Wing anti-Gómez tendency of the Venezuelan exiles, the first years, Revista Izquierdas, 25, octubre 2015, IDEA-USACH, ISSN 0718-5049, pp. $1-28$

en necesidad de conservar en la dirigencia al Secretario General del PRV G.Machado y el editor de "Libertad", S. de la Plaza.

El plan mexicano de formación del PCV fue ponderado, tomando en cuenta y de manera objetiva las posibilidades. El plan incluía los siguientes puntos: reorganización del trabajo de la fracción comunista del PRV para proteger la línea política del futuro Partido Comunista; vincular estrechamente el movimiento venezolano con el de Colombia, con una organización que podría unir legalmente a los exiliados procedentes de ambos países; transformación del grupo comunista venezolano en el Partido Comunista sobre la base de los militantes venezolanos en los PP.CC. de México, EE.UU., Francia; establecimiento de los contactos con los obreros inmigrantes e inicio del trabajo para formar el PCV en el interior venezolano; la edición del periódico "El Obrero". Se proponía convertir la fracción comunista del PRV en una estructura consolidada que actuara guiándose por la línea política de la Comintern. ${ }^{51}$ Sólo después de esto se consideraba posible realizar una revolución social en Venezuela.

El emisario de la Comintern, Grollman ("Pedro"), creía necesario organizar el Partido Comunista en base al PRV, 'el partido de pequeña burguesía bajo el control de comunistas', de acuerdo con la actitud asumida por del PCM. Según las memorias de G. Machado, el enviado de Moscú declaró que no se podía engañar a la historia, que el partido de la pequeña burguesía iba a aparecer de todas formas, entonces, sería mejor que esté controlado por la Comintern. ${ }^{52}$

\section{El 'salto de Curazao" y el fin del PRV 'comunista'}

Sin embargo, los exiliados venezolanos (entre ellos, los comunistas) no renunciaron a la idea de la lucha armada contra Gómez, y el PCM, aunque no estaba apoyando a sus partidarios venezolanos directamente, al menos no obstruía sus actividades. Los motivos de dicha actitud ambigua eran obvios: los comunistas mexicanos seguían reconociendo la importancia del exilio venezolano y esperaban usarlo para desplegar un frente antiimperialista dentro de su propio país y por toda Latinoamérica. El PCM seguía

\footnotetext{
51 "Resolution of the Mexican Communist Party on the Venezuelan question on the basis of the letter addressed by the Latin American Secretariat of the C.I. to the Venezuelan communists", Mexico, D. F., April 16th 1929. RGASPI, f. 495, inv. 108, exp. 102, ff. 1-2.

52 "Report of Comrade Machado", November of 1929. RGASPI. F. 495, inv. 107, exp. 11, f. 6. El representante de la Comintern en su aproximación al asunto venezolano asumió la actitud evaluada posteriormente por Moscú como 'oportunismo de izquierda'. Es una paradoja histórica: mientras el 'camarada Pedro' (Grollman) en México definía los destinos de los dirigentes de la sección mexicana de la III Internacional (acusados por él de "desviaciones a la derecha"), Moscú estaba resolviendo el futuro de Grollman. El 16 de agosto de 1929 la delegación del Partido Comunista de la URSS (bolchevique) en la Comintern adoptó el acuerdo de llamar a Grollman a su patria y retirarlo de la Comintern. Tras una "autocrítica" emprendida por Grollman, le permitieron seguir trabajando como asistente del Secretario del CEIC, Osip Pyatnitzky. No obstante, en marzo de 1933 él fue expulsado del Partido Comunista por 'derechista' y condenado a tres años de cárcel. Otra vez fue arrestado en 1937 junto con Pyatnitzky y esta vez acusado de prestar apoyo financiero a Trotsky, por lo que fue ejecutado. - Lazar Jeifets, Víctor Jeifets y Peter Huber 143-144.
} 
Víctor Jeifets y Lazar Jeifets, La inserción internacional de la izquierda comunista anti-gomecista en el exilio venezolano, primeros años - The international insertion of the Communist Left-Wing anti-Gómez tendency of the Venezuelan exiles, the first years, Revista Izquierdas, 25, octubre 2015, IDEA-USACH, ISSN 0718-5049, pp. $1-28$

estimando al PRV como un partido "anticaudillista" y antiimperialista muy diferente de la oposición liberal antigomecista.

En el año 1928 los disturbios estudiantiles, huelgas de solidaridad, la rebelión de los cadetes de la escuela militar y protestas en la guarnición caraqueña demostraron la vulnerabilidad del régimen de J.V. Gómez. Los líderes del PRV evaluaron estos acontecimientos como el inicio de la crisis política del gobierno autoritario. Especial impresión causó la participación de los cadetes y varios oficiales en las acciones de protesta. Según la evaluación hecha por los historiadores rusos, a partir de aquel momento la lucha contra Gómez se extendió a nuevas fuerzas sociales. ${ }^{53}$

El cambio de situación en Venezuela estimulaba a los adeptos del derrocamiento armado de la dictadura a actuar. Una de estas tentativas, conocida como Ataque de Cumaná o Revolución "El Falque"54 fue organizada por la Junta Suprema de Liberación Venezolana que había sido creado en 1929 en Ginebra. El general Román Delgado Chalbaud fue asignado como dirigente militar de esta expedición preparada en Europa. ${ }^{55}$ Según la opinión de G. Machado, la junta se componía de "los militares que antes habían servido al dictador y tenían miedo ante la consolidación de los comunistas en Venezuela". ${ }^{56} \mathrm{Su}$ evaluación fue demasiado categórica. Es cierto que los ex-militares y ex-funcionarios del régimen eran parte considerable de la junta. A Delgado Chalbaud en sus actividades antidictatoriales le apoyaban sus antiguos amigos del banco Crédit Française y de la Casa Bancaria de Dreyfus, así como el magnate petrolero venezolano Antonio Aranguren. Sin embargo, el fundador de la junta fue el publicista José Rafael Pocaterra, muy cercano al sector de izquierda del exilio venezolano. ${ }^{57}$

La segunda expedición fue encabezada en 1929 por el general E. Arévalo Cedeño, que ya tenía experiencia en dirigir una operación similar en 1921. En abril del mismo año el general José Rafael Gabaldón empezó la rebelión armada desde su hacienda. Todas estas

\footnotetext{
53 "Report of Comrade Machado", November 1929, f.5; Nikolái P. Kalmykov, et al. 1997: 283-284.

${ }^{54}$ La expedición partió hacia las costas de Cumaná desde el puerto polaco Gdynia en el barco "El Falque".

${ }^{55}$ R. Delgado Chalbaud participó en el golpe de estado del 19 de diciembre de 1908, que había llevado a J.V. Gómez al poder. Luego realizó las negociaciones en Europa sobre la participación del capital extranjero en la modernización del sistema bancario de Venezuela. En el año 1913 inicio el movimiento ilegal contra la reelección de Gómez, fue arrestado y pasó 14 años en la cárcel "La Rotunda". Falleció en combate el 11 de agosto de 1939 en Cumaná.

En la expedición participaba su hijo, Carlos Delgado Chalbaud. Tras la derrota de los rebeldes, regresó a Francia donde se recibió como ingeniero. Se casó con la comunista francesa de origen romano Lucía Levine. Planificó una nueva incursión armada a Venezuela. Después de la muerte de J.V. Gómez regresó a su patria, luego estudió en la Escuela Superior Militar en Versailles y formó parte de las unidades ingenieras del ejército venezolano. Participó activamente en el golpe de estado del 18 de octubre de 1945. Fue miembro de la Junta Revolucionaria y ministro de la flota. Fue ministro de guerra en el gobierno de R. Gallegos y luego encabezó a la Junta Militar que derrocó a Gallegos, en 1948. Fue asesinado el 13 de noviembre de 1950 // "Por qué mataron a Delgado Chalbaud?"14 de Noviembre de 2010 / http://www.chavez.org.ve/temas/noticias/delgadochalbaud-efemerides; "Carlos Delgado Chalbaud"

http://www.fundacionjoseguillermocarrillo.com/sitio/disdelgadochalbaud.php; "Román Delgado Chalbaud" // http://www.venezuelatuya.com/biografias/roman_delgado_chalbaud.htm

56 "Report of Comrade Machado", November of 1929, f. 5.

${ }^{57}$ Posteriormente fue el primer embajador de Venezuela en la URSS. - Nil Nikandrov, "Diplomáticos de Stalin en Caracas", Latinskaia Amerika3 (2005).
} 
Víctor Jeifets y Lazar Jeifets, La inserción internacional de la izquierda comunista anti-gomecista en el exilio venezolano, primeros años - The international insertion of the Communist Left-Wing anti-Gómez tendency of the Venezuelan exiles, the first years, Revista Izquierdas, 25, octubre 2015, IDEA-USACH, ISSN 0718-5049, pp. $1-28$

operaciones fracasaron. Sin embargo, estos acontecimientos claves de la historia venezolana no pueden eclipsar el hecho de que la primera tentativa de incursión armada fue realizada en 1929 por los miembros del PRV, liderados por G. Machado. Dos días después de una cita con Grollman en la Ciudad de México (el 15 de abril de 1929), el Secretario General del PRV junto con un grupo de seguidores partió para la isla Curazao, una colonia holandesa donde muchísimos venezolanos trabajaban para Royal Dutch Shell. La célula del PRV en Villemstad fue formada en octubre de 1928 por Hilario Montenegro, asesinado en enero de 1929. La llegada de Machado a la isla contribuyó a la reanudación de las labores de la célula. Las cortas pláticas entabladas entre el Secretario General del PRV y los seguidores, les convencieron de apoderarse de armas e iniciar una expedición al interior de Venezuela. El jefe militar del alzamiento era el general Rafael Simón Urbina, un nacionalista venezolano con sentimientos antimperialistas. Obviamente, no era comunista, sin embargo, estaba enterado sobre la ideología profesada por Gustavo Machado. Lo mismo se puede decir sobre otros dirigentes de la acción armada.

El 8 de junio de 1929 los rebeldes se apoderaron de una manera veloz de la fortaleza de Villemstad, detuvieron al gobernador y jefe de la policía militar. Varios obreros venezolanos -al enterarse sobre el combate- se acercaron a la fortaleza, esperando obtener armas. Sin embargo, les esperaba una sorpresa triste, al igual que a los dirigentes del alzamiento: en la fortaleza apenas lograron conseguir 250 rifles con 1,500 cartuchos. Como sea, Curazao se convirtió por unas horas en el centro de la revolución venezolana. Los rebeldes subieron a bordo del "Maracaibo", el vapor estadounidense que acababa de llegar a la isla. Es precisa la nota del periodista colombiano Plinio Apuleyo Mendoza: Machado, por fin, encontró el barco que estuvo buscando durante diez años en Paris, México, Santo Domingo y Moscú. ${ }^{58}$ Pero era tarde, y - no cabe la menor duda- era el momento de recordar los proyectos fallidos de obtener el apoyo financiero de la Comintern y los armas prometidos por las autoridades mexicanas. Las fuerzas de la expedición mal armada eran escasas, y el espíritu revolucionario no podía compensar la falta de balas.

El 9 de junio los rebeldes desembarcaron cerca de La Vela del Coro en el Estado venezolano de Falcón y en unas horas se enfrentaron con las tropas gomecistas. Dentro de cuatro días las municiones y armas se acabaron y los expedicionarios tuvieron que esconderse en las montañas y pueblos cercanos. Sin embargo, los peones locales estaban poco interesados en cualquier ideología. El reto de penetrar a las regiones industriales y emprender un trabajo de organización del PCV resultaba ser prácticamente imposible. La única esperanza para Machado era el reclutamiento de los peones que antes habían trabajado en Maracaibo, pero regresaron a causa de la crisis económica; el Secretario General del PRV quería apoyarse en sus sentimientos 'anti-gringos'. Estos planes tampoco prosperaron.

Efectivamente, "el asalto de Curazao" era una acción desesperada, mal preparada y casi sin recursos. La impaciencia revolucionaria dominaba sobre los cálculos políticos, y los dirigentes del PRV ya estaban seguros de que sólo podrían contar con ellos mismos. Además, Machado no podía omitir el hecho de que varios de sus ex y todavía aliados, los oficiales Arévalo Cedeño, José Rafael Gabaldón, Delgado Chalbaud, eran caudillos, muy

\footnotetext{
${ }^{58}$ Apuleyo Mendoza, Plinio. “Machado, de aristócrata a líder rojo”, en Machado, Gustavo: 169.
} 
Víctor Jeifets y Lazar Jeifets, La inserción internacional de la izquierda comunista anti-gomecista en el exilio venezolano, primeros años - The international insertion of the Communist Left-Wing anti-Gómez tendency of the Venezuelan exiles, the first years, Revista Izquierdas, 25, octubre 2015, IDEA-USACH, ISSN 0718-5049, pp. $1-28$

típicos para Venezuela y toda América Latina. Una alianza duradera con los comunistas era imposible por serias divergencias ideológicas. Cualquiera de estos caudillos esperaba ansiosamente sustituir a Gómez con otro gobierno, más 'suave', pero de todos modos, caudillista. Gustavo Machado no era caudillo, sin embargo, era militante comunista, y como discípulo de la revolución mundial, intentaría construir la dictadura del proletariado, según los planteamientos de la Comintern. Esas circunstancias harían inevitable una guerra civil.

La derrota del famoso "asalto de Curazao" puso punto final a los planes de los comunistas venezolanos de derrocar el régimen gomecista por la vía de la expedición armada. Fue el inicio del fin del PRV. Los comunistas del GCR dentro del PRV se enfrentaron con la necesidad de reconsiderar las perspectivas de la lucha antidictatorial y replantear su línea de comportamiento en el momento de la caída esperada de J.V.Gómez. A partir de aquel momento, cesó la realización del plan venezolano-mexicano de formar un Partido Comunista dentro de Venezuela. La Comintern no asumió su dosis de culpa en la derrota de los exiliados comunistas venezolanos, sin embargo, quiso encontrar responsables por el fracaso. No tardó mucho en definir que la culpa era del PRV y -en lo personal- de Gustavo Machado. Efectivamente, el destino del PRV fue resuelto meses y años antes de la expedición desesperada. Lo decidieron los funcionarios del partido comunista mundial en Moscú, Nueva York y la Ciudad de México. Otro plan de formación del PCV, elaborado en Moscú, entró en vigor abriéndose una nueva página de la historia de la izquierda venezolana y borrando de esta crónica a los precursores del comunismo venezolano.

\section{Consideraciones finales}

A través de este estudio, hemos analizado las relaciones establecidas entre varios grupos de la izquierda comunista venezolana en el exilio desde su inserción en la órbita del comunismo internacional. Este análisis deja en evidencia que los contactos entre los comunistas venezolanos y la Comintern fueron establecidos mucho antes de la formación oficial del Partido Comunista. Muestra también que en aquel entonces el modelo de desarrollo del futuro PCV era muy diferente de los 'clásicos' Partidos Comunistas. Se trataba de una alianza amplia con las fuerzas revolucionarias que rebasaban los estándares marxistas y no siempre se cuadraban con sus dogmas. La capacidad del Grupo Comunista Revolucionario dentro del PCV de captar nuevos aliados entraba en obvio desacuerdo con las costumbres y reglas de la Comintern, cuyo patrocinio ideológico y financiero era requerido ansiosamente por los comunistas venezolanos. En ese sentido, podemos concluir que la sede de revolución mundial estaba ante un dilema: aceptar a los comunistas venezolanos tal como eran y, en consecuencia, correr el riesgo de que la futura revolución antigomecista estuviera fuera del control de Moscú, o cambiar el modelo de formación del PCV. La Comintern, según se desprende del análisis realizado, optó por la segunda opción. Moscú insistió en la creación del PCV dentro de Venezuela en vez de su construcción sobre los grupos de exiliados en el exterior y deshizo los planes del "camino garibaldino" sugeridos por los hermanos Machado y Salvador de la Plaza. El intento fallido de derrocar a la dictadura gomecista (realizada por Gustavo Machado a pesar de la actitud negativa 
Víctor Jeifets y Lazar Jeifets, La inserción internacional de la izquierda comunista anti-gomecista en el exilio venezolano, primeros años - The international insertion of the Communist Left-Wing anti-Gómez tendency of the Venezuelan exiles, the first years, Revista Izquierdas, 25, octubre 2015, IDEA-USACH, ISSN 0718-5049, pp. $1-28$

expresada por la Comintern acerca de tal expedición) inevitablemente llevó al debilitamiento del núcleo comunista dentro del PRV y del PRV en su conjunto. Consecuentemente, el PCV formado en los años treinta ya se basaba principalmente sobre las directivas expedidas por los dirigentes de la III Internacional y la cúpula de sus líderes era visiblemente diferente de los cuadros comunistas de la década anterior.

\title{
FUENTES
}

\author{
Recibido: 4 marzo 2015 \\ Aceptado: 23 junio 2015
}

\section{ARCHIVOS:}

CEMOS Centro de Estudios del Movimiento Obrero y Socialista, México, D.F.

RGASPI Archivo Estatal de Historia Social y Política, Moscú (en ruso: РГАСПИ)

AVPRF Archivo de Política Exterior de la Federación Rusa, Moscú (en ruso: АВПРФ).

"A compañeros miembros del CEC y a los miembros de todas las Locales del "Partido Revolucionario Venezolano". Paris, 26 de Febrero de 1930. RGASPI, Moscú. F. 495, inv. 107, exp. 16, f. 4.

"Autobiografía de G. Machado". 1952. RGASPI, F. 495, inv.200, exp. 16 (Expediente personal de G. Machado.). ff. 161-162;

"La carta del CC de PCM al Secretariado Latino de Comintern". 14 de julio de 1928. RGASPI, F.495, inv. 108, exp. 84, ff. 42-42 vuelta (el mismo documento en: CEMOS. México, D.F. Colección PCM, caja 3, folio 17, f.1. 182, f. 8.

"Carta de Raymond [B. Mijailov]". Julio de 1926. RGASPI, F. 495, inv.19, exp.

"Carta del representante de la Comintern en México, A. Stirner, al jefe del Secretariado Latino J. Humbert-Droz". 27 de mayo de 1927. RGASPI, F. 495, inv.19, exp. 181, ff. 92-100.

La carta del vice-comisario popular de asuntos exteriores de la URSS, Máxim Litvinov, al Secretariado del CEIC". 3 de septiembre de 1926. RGASPI. F. 495, inv.200, exp. 16 (Carpeta personal de G. Machado), f. 220.

"La colonia venezolana. La Habana (Cuba). Carta Abierta". RGASPI. F. 495, inv. 107, exp. 10, f. 11.

"Diario del representante plenipotenciario". Sin fecha. Archivo de Política Exterior de la Federación Rusa (AVPRF), Moscú. Departamento Mexicano, F. 0110, inv. 6, exp. 1, carpeta 101, f. 73.

'Flores Cabrera, the President of the Venezuelan Workers' Union to Mr. Joseph Stalin, the Secretary of the Central Committee". November, 11, of 1926. RGASPI. F. 534, inv. 7, exp. 95, ff. 1-3.

"G. Machado al Comité Ejecutivo de la Internacional Comunista". RGASPI, F. 495, inv.107, exp. 3, f. 58.

"Grupo Continental Revolucionario. Salvador de la Plaza, Secretario General". México, 1926. RGASPI, f. 495, inv.107, exp. 3, f. 35. 
«Informe de Salvador de la Plaza”. Moscú, 5 de enero de 1928. RGASPI. F. 534, inv. 7, exp. 95, ff. 32 .

"Lettre a Ricardo Martínez, Moscou, U.R.S. S ». Barranquilla, Colombie, 20 juin 1928. RGASPI, inv. 107, exp. 8, f. 61.

Mella, Julio Antonio, "L'information sur la Ligue Anti-Imperialiste PanAmericain”. Moscou, 25 de Mars du 1927. RGASPI. F. 495, inv. 18, exp. 604, f. 7.

"Partido Revolucionario Venezolano. Credencial del compañero Salvador de la Plaza". México, D.F., 8 de octubre de 1927. RGASPI, F. 495, inv.107, exp. 3, f. 53.

"Programme du Parti Révolutionnaire Venezuelien. Explication de quelques uns des points des principes fondamentaux de la Revolution Venezuelienne objet du Parti Revolutionnaire Venezuelien. (P.R.V.)".Mexique, 31 mai 1927. RGASPI, F. 495, inv. 107, exp. 3, f. 40. 11, f. 6.

"Report of Comrade Machado", November of 1929. RGASPI. F. 495, inv. 107, exp.

"Resolution d'expulsion du Général Arevalo C. du Parti Revolutionnaire Vénézulien". RGASPI. F. 495, inv. 107, exp. 3, f. 50.

"Resolution of the Mexican Communist Party on the Venezuelan question on the basis of the letter addressed by the Latin American Secretariat of the C.I. to the Venezuelan communists". Mexico, D.F., April 16th 1929. RGASPI. F. 495, inv. 108, exp. 102, f. 1.

"Salvador de la Plaza al Camarada Alfredo Stirner". México, 23 de junio de 1926. RGASPI. F.495, inv. 197, exp. 3, f. 15.

"Salvador de la Plaza a Rafael Carrillo". México, 1 de abril de 1926. RGASPI, F. 495, inv.107, exp. 3, f. 3.

PRENSA:

Historia. Revista electrónica científica y educativa, Moscú

Izquierdas, Revista electrónica, Santiago de Chile

Izvestia, Moscú

Latinskaia Amerika, Moscú

El Libertador, México

Mezhdunarodnoie rabocheie dvizhenie, Moscú

Memoria, México

Revista CS, Cali

Tribuna Popular, Caracas

\section{RECURSOS ELECTRONICOS:}

Arias, René. «Salvador de la Plaza: clave para la historia del socialismo en Venezuela », Cuadernos Americanos, núm. 124, México, 2008. http://www.cialc.unam.mx/cuadamer/textos/ca124-143.pdf

COMINTERN Electronic Archives (www.comintern-online.com)

Mattié, Mailer. "Salvador de la Plaza, un pensador revolucionario venezolano en el olvido". - http://laclase.info/teoria/salvador-de-la-plaza-un-pensador-revolucionariovenezolano-en-el-olvido 27/12/2009 - 13:46 

the Venezuelan exiles, the first years, Revista Izquierdas, 25, octubre 2015, IDEA-USACH, ISSN 0718-5049, pp. $1-28$

Morán Beltrán, Lino; Velásquez, Lorena, y Meleán, Vileana. “Gustavo Machado y los orígenes del marxismo en Venezuela", Revista de Filosofía, vol. 23, núm. 49, Maracaibo, $2005 . \quad$ - $\quad$ http://www.scielo.org.ve/scielo.php?pid=S0798$\underline{11712005000100002 \& \text { script }=\text { sci_arttext }}$

SALVADOR DE LA PLAZA, Archivo electrónico. http://salvadordelaplaza.faces.ula.ve

Sant Roz, José. Conozca quién fue el gran General Emilio Arévalo Cedeño // http://www.aporrea.org/actualidad/a40327.html [consultado 10.08.2013]

Sant Roz, José. La odisea equinoccial de Emilio Arévalo Cedeño. http://www.aporrea.org/actualidad/a56679.html 09.05.2008. 06:41PM [consultado 03.01.2015]

Por qué mataron a Delgado Chalbaud? 14 de Noviembre de 2010 / http://www.chavez.org.ve/temas/noticias/delgado-chalbaud-efemerides [consultado 20.12.2010]

Carlos Delgado Chalbaud //http://www.fundacionjoseguillermocarrillo.com/sitio/disdelgadochalbaud.php [consultado: 25.04.2013]

Román Delgado Chalbaud //

http://www.venezuelatuya.com/biografias/roman_delgado_chalbaud.htm

[consultado 12.06.2013]]

\section{BIBLIOGRAFIA:}

Alexander, Robert J. Communist Party of Venezuela. Stanford: Hoover Institution Press-Stanford University Press, 1969.

Belmonte Guzmán, Amalio. Ensayo sobre la historia política de Venezuela, 19171968. Caracas: Academia Nacional de la Historia, 1981.

Boersner, Demetrio. Análisis del Partido Comunista en Latinoamérica y Venezuela. Caracas: Univ. Popular Alberto Carnevali, 1961.

Caballero, Manuel. Entre Gómez y Stalin. Caracas: Universidad Central de Venezuela, Consejo de Desarrollo Científico y Humanístico, 1989.

Caballero, Manuel. La Internacional Comunista y la revolución latinoamericana. Caracas: Editorial Nueva Sociedad, 1987.

Caballero, Manuel. La Internacional Comunista y América Latina: La sección venezolana. México: Pasado y Presente, 1978. 1925.

Cárdenas, R. "El Congreso Obrero Panamericano", El Libertador, núm. 1, México,

Cobo, Lourdes. Estudio de las relaciones internacionales en Venezuela. Caracas: Ed. Ministerio de Relaciones Exteriores, 1982.

Faria, Jesús. Stanovleniie kommunista. Vospominaniia. Moscú: Izdatelstvo politicheskoi literatury, 1983.

Fornet-Betancourt, Raúl. Transformación del Marxismo: Historia del Marxismo en América Latina, México: Ed. Plaza y Valdés, 2001.

Fuenmayor, Juan Bautista. Aportes para la historia del P.C.V. Maracaibo: Biblioteca de Documentos Históricos, 1971. 
Víctor Jeifets y Lazar Jeifets, La inserción internacional de la izquierda comunista anti-gomecista en el exilio venezolano, primeros años - The international insertion of the Communist Left-Wing anti-Gómez tendency of the Venezuelan exiles, the first years, Revista Izquierdas, 25, octubre 2015, IDEA-USACH, ISSN 0718-5049, pp. $1-28$

Fuenmayor, Juan Bautista. 1928-1948. Veinte años de política. Caracas: s.e., 1968.

García Ponce, Guillermo. Memorias de un general de la utopía. La increíble historia de un venezolano excepcional, Eduardo Machado y de sus luchas revolucionarias en Venezuela, Cuba, México, España, Estados Unidos y en la Internacional Comunista. Caracas: Cotragraf, 1992.

Goldenberg, Boris. Kommunismus in Lateinamerika. Stuttgart, Berlin, Köln, Mainz: Kohlhammer, 1971.

Jeifets, Víctor y Jeifets, Lazar. "Los orígenes del Partido Comunista del Ecuador y la Tercera Internacional”, Izquierdas, núm. 6, Santiago de Chile, 2010.

Jeifets, Víctor y Jeifets, Lazar. "El giro a la izquierda en América Latina y el nacimiento del nuevo bolivarianismo: las tradiciones de la Komintern y la actualidad", Revista CS, núm. 4, Cali, 2009.

Jeifets, Víctor y Jeifets, Lazar, "Haya de la Torre, ¿un comunista latinoamericano?”, Historia: Revista electrónica científica y educativa, núm. 6, Moscú, 2011.

Jeifets, Lazar, Víctor Jeifets y Peter Huber. La Internacional Comunista y América Latina, 1919-1943. Diccionario biográfico. Moscú: Instituto de Latinoamérica de la Academia de Ciencias / Ginebra: Institut pour l'histoire du communisme, 2004. 1999.

Kalmykov, N.P. et al. (ed.). Historia de América Latina, 1918-1945.Moscu: Nauka,

Kalmykov, N.P. et al. (ed.). Komintern y América Latina. Sbornik dokumentov. Moscú: Nauka, 1998.

Key Sánchez, Fernando. Fundación del Partido Comunista de Venezuela: (trabajo elaborado para el Comité Central y el VI Congreso del P.C.V.). Caracas: Fondo Editorial "Carlos Aponte", 1980.

Key Sánchez, Fernando. Fundación del Partido Comunista de Venezuela. Prólogo de E. Gallegos Mancera. Segunda edición ampliada. Caracas: Fondo Editorial "Carlos Aponte", 1984.

Libro Rojo del General López Contreras. 1936. Documentos robados por espías de la policía política. Caracas: Ávilarte, 1975.

Machado, Gustavo. "El asalto a Curazao", en El comienzo del debate socialista, El pensamiento político del siglo XX. Documentos para su estudio. Tomo XIII. Caracas: Ediciones Congreso de la República, 1983.

Machado, Gustavo. De oligarca a comunista. 1914/1974. Caracas: Ediciones Centauro, 1975.

Melcher, Dorothea.Estado y movimiento obrero en Venezuela: represión e integración hasta 1948. Caracás: Academía Nacional de la Historia-Universidad de los Andes, 1992.

Melgar Bao, Ricardo. "El exilio venezolano en México". Memoria. Revista Mensual de Política y Cultura, núm. 110, México, 1998.

Nikandrov, Nil. "Diplomáticos de Stalin en Caracas", Latinskaia Amerika, núm. 3, Moscú, 2005.

Partido Comunista de Venezuela. «Creación del Partido Comunista de Venezuela», en Documentos que hicieron historia. Caracas: Presidencia de la República, 1962. 
Víctor Jeifets y Lazar Jeifets, La inserción internacional de la izquierda comunista anti-gomecista en el exilio venezolano, primeros años - The international insertion of the Communist Left-Wing anti-Gómez tendency of the Venezuelan exiles, the first years, Revista Izquierdas, 25, octubre 2015, IDEA-USACH, ISSN 0718-5049, pp. $1-28$

Pegusheva, Lidia América Latina: "panamericanismo" en el movimiento obrero. Moscú: Nauka, 1974.

Pérez Vila, Manuel et al. Política y Economía en Venezuela (1810-1976). Caracas: Ed. Foundation John Boulton, 1976.

Pujals, Sandra. "A Soviet Caribbean: The Comintern, New York's Internationalist Diaspora, and the Forging of Post-War Caribbean Visions, 1931-1936", Russian History núm. 41 (2014).

Rodríguez Gallad, Irene. Compilación, Introducción, Cronología y Notas. Archivo de Salvador de la Plaza. Tomo I-II. Caracas, Ediciones Centauro, 1992.

Shestoi Vsemirnyi kongress Kommunisticheskogo Internatsionala. Stenograficheskii otchet. Vyp. 4. Moscú: Gosizdat, 1928 (El VI Congreso Mundial de la Internacional Comunista. Acta taquigráfica).

Sosa, Arturo y Lengrand, Eloi. Del garibaldismo estudiantil a la izquierda criolla. Los orígenes marxistas del proyecto de A.D. (1928-1935), Caracas: Ediciones Montalvo, 1981.

Vasconcelos, José. Discursos 1920-1950. México: Ediciones Botas, 1950. 